\title{
anu \\ Can GPM IMERG Capture Extreme Precipitation in North China Plain?
}

\author{
Dasheng Zhang ${ }^{1,+}$, Mingxiang Yang ${ }^{2}$, Meihong Ma ${ }^{3,4,+}$, Guoqiang Tang ${ }^{5, *} \mathbb{C}$, Tsechun Wang ${ }^{6}$, Xun Zhao ${ }^{1}$, \\ Suying Ma ${ }^{1}$, Jin $\mathrm{Wu}^{7}{ }^{7}$ and Wei Wang ${ }^{3}$
}

check for updates

Citation: Zhang, D.; Yang, M.; Ma, M.; Tang, G.; Wang, T.; Zhao, X.; Ma, S.; Wu, J.; Wang, W. Can GPM IMERG Capture Extreme Precipitation in North China Plain? Remote Sens. 2022, 14, 928. https://doi.org/10.3390/rs14040928

Academic Editor: Joan Bech

Received: 27 December 2021

Accepted: 8 February 2022

Published: 14 February 2022

Publisher's Note: MDPI stays neutral with regard to jurisdictional claims in published maps and institutional affiliations.

Copyright: (C) 2022 by the authors. Licensee MDPI, Basel, Switzerland. This article is an open access article distributed under the terms and conditions of the Creative Commons Attribution (CC BY) license (https:// creativecommons.org/licenses/by/ $4.0 /)$.
1 Hebei Institute of Water Resources, Shijiazhuang 050051, China; 18501317443@163.com (D.Z.); 18931131557@163.com (X.Z.); 18931136506@163.com (S.M.)

2 China Institute of Water Resources and Hydropower Research, Beijing 100038, China; yangmx@iwhr.com

3 School of Geographic and Environmental Sciences, Tianjin Normal University, Tianjin 300387, China; mamh@tjnu.edu.cn (M.M.); mxyuskrisi@163.com (W.W.)

4 Tianjin Key Laboratory of Water Resources and Environment, Tianjin Normal University, Tianjin 300387, China

5 Center for Hydrology, University of Saskatchewan, Canmore, AB T1W 3G1, Canada

6 Institute of Remote Sensing and Geographic Information System, School of Earth and Space Sciences, Peking University, Beijing 100871, China; jason100168331@pku.edu.cn

7 College of Architecture and Civil Engineering, Beijing University of Technology, Beijing 100124, China; wujin@bjut.edu.cn

* Correspondence: guoqiang.tang@usask.ca

+ Co-first author.

\begin{abstract}
Extreme precipitation events (EPE) often cause catastrophic floods accompanied by serious economic losses and casualties. The latest version (V06) of the Integrated Multi-satellite Retrievals for Global Precipitation Measurement (GPM IMERG) provides global satellite precipitation data from 2000 at a higher spatiotemporal resolution with improved quality. It is scientifically and practically important to assess the accuracy of the IMERG V06 in capturing extreme precipitation. This study evaluates the two widely used products of IMERG during 2000-2018, i.e., IMERG late run (IMERG-L) and IMERG final run (IMERG-F), in the densely populated and flood-prone North China Plain. The accuracy of the IMERG V06 is evaluated with ground measurements from rain gauge stations at multiple scales (hourly, daily, and seasonally). A novel target tracking method is introduced to extract three-dimensional (3D) extreme precipitation events, and the near-real-time uncalibrated PERSIANNCCS (Precipitation Estimation from Remotely Sensed Information using Artificial Neural Networks Cloud Classification System) and GSMAP (Global Satellite Mapping of Precipitation) satellite data are added to further evaluate IMERG's performance during extreme precipitation. Finally, for flash flood events induced by extreme rainfall in the Hebei Province from 15 to 23 July 2016, the accuracy of capturing the event with IMERG-F and IMERG-L was verified. Results reveal that IMERG-F is better than IMERG-L at all investigated scales (hourly, daily, and seasonally), but the difference between the two products is less at higher time resolutions. Both products manifest decreased performance when capturing 3D extreme precipitation events, and comparatively, IMERG-F performs better than IMERG-L. IMERG-F exhibits a distinct discontinuity in extreme precipitation thresholds between land and ocean, which is a limitation of IMERG-F not documented in previous studies. Moreover, IMERG-L and IMERG-F are comparable at an hourly scale for some metrics, which is beyond the expectation that IMERG-F is notably better than IMERG-L. This study provides a scientific basis for the performance of satellite precipitation products and contributes to guiding users when applying global precipitation products.
\end{abstract}

Keywords: IMERG; object tracking; extreme precipitation; North China Plain 


\section{Introduction}

Precipitation is a key component of the global water cycle [1]. Climate change has caused an increase in the frequency and quantity of precipitation, which has severely threatened people's lives and properties [2-4]. High-quality precipitation data are of great significance to industrial and agricultural production, water conservancy development, drought, and flood prevention [5]. The traditional method for obtaining precipitation data is to install a network of rain gauge stations with a specific spatial density. Although accurate precipitation can be obtained at each station, the uneven distribution of rain gauge stations and the spatial discontinuity of precipitation data have obvious limitations [6,7]. Remote-sensing-based methods using radars or satellites have been increasingly applied to estimate precipitation and spatial distribution. However, many evaluation studies showed that the satellite precipitation estimates often included significant errors, especially greater uncertainty when estimating extreme precipitation [8]. Therefore, accurately estimating extreme precipitation and understanding its spatiotemporal evolution is critical [9].

With the development of satellite remote sensing technology and precipitation retrieval algorithms, satellite precipitation products have experienced significant progress [10,11]. The most typical example could be the transition from the Tropical Rainfall Measuring Mission (TRMM) to the Global Precipitation Measurement (GPM) mission [12]. The Integrated Multi-Satellite Retrievals for GPM (IMERG) provides improved precipitation data by integrating microwave and infrared data from the GPM satellite constellation [13]. Compared to TRMM products, IMERG products have higher temporal (half-hourly) and spatial resolution $\left(0.1^{\circ}\right)$ and improved capability for monitoring extreme precipitation [14-16]. Since the release of IMERG precipitation products in 2014, many studies evaluating different versions of IMERG precipitation products have been conducted at various spatial (e.g., watersheds, countries, continents, and the globe) and temporal scales (e.g., half-hourly, hourly, daily, and monthly) [17-26].

IMERG is one of the most widely used satellite precipitation products and has been extensively evaluated in China. For example, Tang et al. evaluated IMERG precipitation products in mainland China and revealed that IMERG precipitation products perform better than TMPA (TRMM Multi-satellite Precipitation Analysis) precipitation products on both hourly and daily scales; however, in arid areas and high-altitude areas, the accuracy of IMERG precipitation products needs to be improved [8]. Li et al. evaluated the spatial distribution of the IMERG's precipitation detection ability and error structure and the climate dependence of error sources. They concluded that IMERG could capture the spatial pattern of light rain $(<10 \mathrm{~mm} /$ day $)$ in mainland China, but IMERG's performance is poor in areas with complex winter schemes [27]. Yang et al. evaluated IMERG precipitation products with the rain gauge data over Sichuan, China, and concluded that IMERG performed better in estimating the rainfall intensity than detecting the precipitation [28]. Guo et al. compared the IMERG precipitation products before and after the bias-correction/calibration and found that the IMERG-F product calibrated with rain gauge measurements shows improved quality, but it still overestimates the precipitation in western China [29]. Chen et al. compared IMERG and TRMM data in China and found that IMERG has higher accuracy and lower probability of outliers [30]. Foelsche et al. and Wang et al. compared the differences of three different versions of IMERG (V03, V04, and V05) products in mainland China. They found that V04 and V05 demonstrate an improvement over V03; among them, the early and late real-time products of the V04 version are better than the corresponding V03 products, and the V05 final version has the highest accuracy [31,32].

Recently, IMERG products have been updated to the latest version, V06B, which can provide retrospective precipitation estimates from June 2000 to the present. The extended period greatly improves the scope of applications of IMERG products, such as regional and global hydrological simulations of floods. Arshad et al. (2021) explored the advantages and differences of the GPM-IMERG V6 product (real-time and calibrated versions) in Pakistan and verified that the product captures precipitation in the northeast with high accuracy [33]. Tang et al. found that although the quality of IMERG V06 has been greatly improved on the 
hourly scale and reproduces the diurnal cycle well, the snowfall estimation performance of IMERG is poor [10]. The quality of IMERG for the hourly and half-hourly scale in high-latitude and high-altitude areas and the precipitation estimates in arid climates areas need to be further improved [8]. Overall, evaluation studies of IMERG V06 are still limited.

Considering that extreme precipitation is a major cause of flood disasters, many studies investigate the performance of IMERG for different precipitation rates, with special attention to heavy precipitation. For example, Sahlu et al. found that IMERG is better than CMORPH on an hourly or daily scale but is worse at detecting heavy rain [34]. He et al. found that IMERG improved the ability to capture moderate-intensity precipitation events and was highly sensitive to extreme precipitation but overestimated extreme precipitation events [35]. Wang et al. found that IMERG captures light rain and moderate rain events well but shows degraded performance in detecting extreme precipitation events [36]. Mahmoud et al. evaluated the performance of GPM IMERG products (i.e., early, late and final run products) in Saudi Arabia, especially the "errors associated" with different precipitation intensities, showing that IMERG products can be an effective surrogate for rainfall data in arid regions [37]. The most common approach to extracting extreme precipitation events is to define intensity thresholds or percentiles (e.g., 90\% and 99\%). However, most studies treat precipitation in each grid and time interval as isolated events, which is easy to implement but ignores precipitation weather systems' temporal and spatial dynamic evolution. Therefore, it is necessary to consider precipitation's temporal and spatial distribution characteristics for a more comprehensive assessment of satellite precipitation products. In this regard, we extracted three-dimensional extreme events using an object-based tracking method to overcome the limitation.

Given the abovementioned limitation of previous studies, this study aims to (1) evaluate the accuracy of the latest version (V06) of IMERG-L and IMERG-F at multiple scales (hourly and daily) with rain gauge measurements from 2000 to 2018 in the North China Plain; (2) introduce object-tracking to explore the accuracy of the post-real-time corrected IMERG-F and near-real-time IMERG-L, PERSIANN-CCS, and GSMAP satellite precipitation data to capture 3D extreme precipitation events and analyze the factors that induce errors; and (3) investigate whether IMERG products can capture typical flood disasters. The North China Plain is selected because it is the most populated region in China. Beijing, the capital of China, is located in the plain. Floods are non-negligible threats in the North China Plain during the rainy season. This study can provide a reference for the application of IMERG and the development of IMERG retrieval algorithms.

\section{Materials and Methods}

\subsection{Study Area}

The North China Plain is located in eastern China, on the lower reaches of the Yellow River, with a latitude of $32^{\circ}-40^{\circ} \mathrm{N}$ and a longitude of $114^{\circ}-121^{\circ} \mathrm{E}$, including Beijing, Tianjin, Hebei, and other provinces. It is an important political and economic center in China. Except for the hills in the Shandong Peninsula, most areas in North China are plains, and the dominant land use type is cultivated land. The North China Plain has a warm, temperate monsoon climate with obvious seasonal changes. Summer is hot and rainy with frequent flooding. During the past 50 years, the average annual temperature in the North China Plain has been $13.1^{\circ} \mathrm{C}$, revealing a significant increasing trend $\left(0.23^{\circ} \mathrm{C} / 10 \mathrm{a}\right)$. The average annual precipitation is about $839 \mathrm{~mm} /$ year, which has a significant decreasing trend, with the fastest decrease in summer and a slight increase in winter precipitation $[38,39]$. Precipitation gradually decreases from the south to the north plain. The North China Plain has scarce water resources and a hot, dry climate. The water resources per capita are only $456 \mathrm{~m}^{3} /$ year, lower than $1 / 6$ of the country's level [40]. The surface water is unevenly distributed in time and space, and the groundwater level continues to drop. The North China Plain is facing a serious water resource crisis and is one of the areas with the greatest water pressure in China, which restricts the sustainable development of the economic, social, and ecological environment. 
Figure 1 shows the elevation and rainfall station distribution map of the North China Plain. Some daily stations are located outside the border of the North China Plain, while the hourly rainfall stations are all located within the boundary. The locations of hourly-scale stations do not overlap with daily-scale rainfall stations due to different data sources.

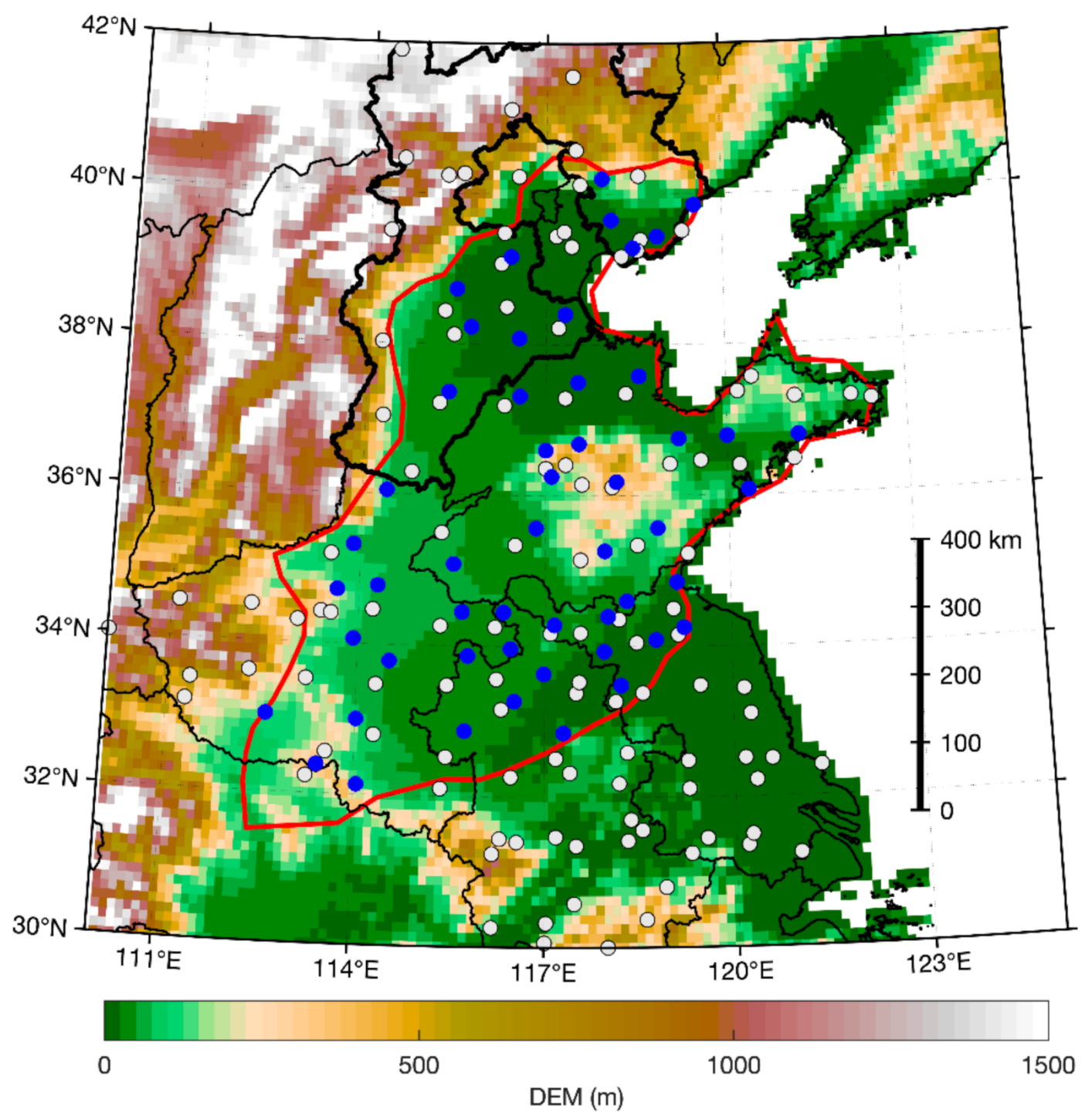

Figure 1. Map of elevation and rain stations in the North China Plain. The red line is the boundary line of the North China Plain. The thick black line is the boundary line of Hebei Province. The white points are daily rain gauges, and the blue points are hourly rain gauges.

\subsection{Data}

\subsubsection{Satellite Precipitation Data}

Since the TRMM satellite was launched in 1997, a large number of satellite precipitation products have been produced, such as GPM IMERG, PERSIANN-CCS, and GSMAP. GPM is the successor of the TRMM program and is composed of about 10 international satellites, producing a new generation of global precipitation (liquid and solid) estimates. Since 12 March 2014, GPM IMERG has provided various levels of precipitation products worldwide [10].

The Level-3 IMERG product (https://gpm.nasa.gov/data/imerg accessed on 20 January 2021) has broader spatial coverage $\left(60^{\circ} \mathrm{N}-\mathrm{S}\right)$ and higher spatiotemporal resolution than the TRMM product $\left(0.1^{\circ}, 0.5 \mathrm{~h}\right.$ VS $\left.0.25^{\circ}, 3 \mathrm{~h}\right)$. IMERG combines all available multi-satellite microwave precipitation estimates through cross-calibration, fusion, and 
interpolation. IMERG precipitation products are one of the most representative and widely used precipitation datasets in the world. According to the timeliness of data generation, it can be divided into "early-run", "late-run", and "final-run" (hereafter IMERG-E, IMERG-L, and IMERG-F). Among them, IMERG-E and IMERG-L products are near-real-time products, released 4 and $12 \mathrm{~h}$ after observation, respectively. IMERG-F is a post-real-time product that is calibrated by monthly ground precipitation data and is released about 3.5 months after observation.

PERSIANN-CCS was developed by the Center for Hydrometeorology and Remote Sensing (CHRS) of the UCI (University of California, Irvine). It utilizes a neural network method to estimate precipitation [41]. PERSIANN-CCS has a spatial resolution of $0.04^{\circ} \times 0.04^{\circ}$ and temporal resolution of $1 \mathrm{~h}, 3 \mathrm{~h}, 6 \mathrm{~h}$, and $24 \mathrm{~h}(1 \mathrm{~h}$ data were used in this study). The PERSIANN-CCS algorithm extracts local and regional cloud features from infrared $(10.7 \mathrm{~mm})$ geostationary satellite images to estimate the finer scale $\left(0.04^{\circ} \times 0.04^{\circ}\right.$ and $30 \mathrm{~min}$ ) rainfall distribution. Global Satellite Mapping of Precipitation (GSMAP) is the product of the Global Precipitation Measurement (GPM) mission, providing global hourly rainfall with a spatial resolution of $0.1^{\circ} \times 0.1^{\circ}$. GSMAP is based on multi-satellite passive microwave radiometer observations like IMERG. PERSIANN-CCS and GSMAP are open access online (https: / / chrsdata.eng.uci.edu/, https: / / sharaku.eorc.jaxa.jp/GSMaP / accessed on 20 January 2021).

\subsubsection{Rain Gauge Data}

Rain gauge measurements are used to evaluate satellite precipitation products. We employed 117 national rain gauges for daily assessment from 2000 to 2018 (Figure 1). Further, we involved hourly rain gauge data in the evaluation, although the number of rain gauges at the hourly scale is smaller than that at the daily scale. For the hourly scale evaluation, the number of national rain gauge data was reduced to 52 in 2018. The rain gauge data have passed strict quality control and, thus, are reliable as the evaluation reference.

\subsubsection{Flash Flood Disaster Data}

Flash flood disaster data mainly came from the official departments of Hebei. However, flash flood validation in this study is qualitative to some extent, mainly because we cannot obtain enough detailed information about the flood event. The selected typical flood case was caused by heavy rainstorms lasting from 18 to 21 July 2016 in Hebei Province, which was the strongest rainstorm in Hebei Province since the "63.8" storm in 1963. The maximum instant rain intensity reached $177 \mathrm{~mm} / \mathrm{h}$. The maximum accumulated rain amounts for $3 \mathrm{~h}$ and $24 \mathrm{~h}$ are $264 \mathrm{~mm}$ and $783.4 \mathrm{~mm}$, respectively. The flood disaster "7.19" was named because the flood happened on 19 July. The main factors triggering flash flood disasters are rainfall, rainfall intensity, slope, topographic factors, and human activities. This flood disaster caused severe landslides and mudslides, resulting in 114 deaths, 111 people missing, 52,900 houses collapsed, 155,000 houses damaged, and 723,500 hectares of crops affected. The direct economic loss was CNH 16.368.

\subsection{Methodology}

The research was divided into four steps (Figure 2). The first step was to download and process PERSIANN-CCS, GSMaP, IMERG-L, and IMERG-F satellite data. The second step was to extract 3D extreme precipitation events. The third step was to carry out the statistical evaluation, which mainly selects hourly or day-scale rain gauge data, evaluates satellite data through quantitative indicators, and analyzes its temporal and spatial distribution and seasonal variability. The fourth step was to conduct qualitative inspections based on typical flood events. 


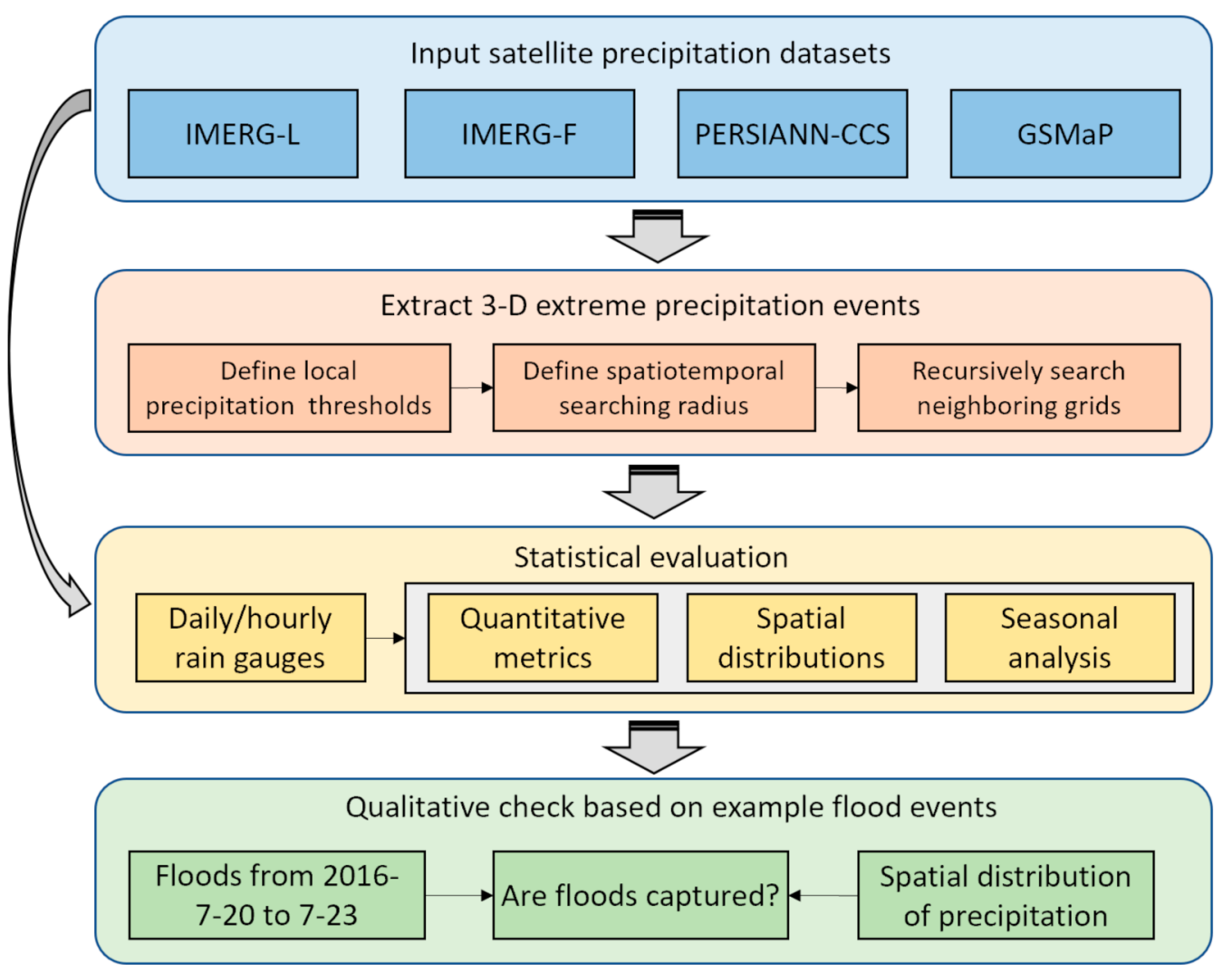

Figure 2. Technical flow chart of article method.

\subsubsection{Evaluation Metrics}

Choosing suitable metrics is essential to evaluate the performance of precipitation data sets. We matched IMERG gridded data with the closest station points. This method is widely used in evaluation studies, although point-area mismatch could lead to uncertainties. The three statistical metrics are (1) mean error $(M E)$, which presents the overall level of satellite data error, and its optimal value is 0 ; (2) correlation coefficient (CC), representing the degree of linear correlation between satellite data and ground station observation data, and the optimal CC value is 1; and (3) the modified Kling-Gupta efficiency coefficient (KGE) $[42,43]$, combining three metrics to achieve a more objective evaluation, and the optimal value is 1 . A positive value of KGE indicates that the estimated value is better than the random estimated value. KGE was originally utilized to measure the consistency between simulated runoff and observed runoff and then extended to the evaluation of environmental variables. KGE decomposes the overall characteristics into three component parameters, which are widely used to evaluate precipitation products. These three metrics are calculated as follows:

$$
\begin{gathered}
C C=\frac{\sum_{i=1}^{n}\left(D_{i}-\bar{D}\right)\left(M_{i}-\bar{M}\right)}{\sqrt{\sum_{i=1}^{n}\left(D_{i}-\bar{D}\right)^{2} \sum_{i=1}^{n}\left(M_{i}-\bar{M}\right)^{2}}} \\
M E=\frac{1}{n} \sum_{n=1}^{n}\left(D_{i}-M_{i}\right)
\end{gathered}
$$

where $n$ is the sample number, $D$ represents satellite precipitation estimate, $M$ represents gauge observed precipitation, $D_{i}$ represents the $i$-th of the evaluated, $M_{i}$ represents the $i$-th of the reference data, $\bar{D}$ represents mean of $D_{i}$, and $\bar{M}$ represents mean of $M_{i}$.

$$
\mathrm{KGE}^{\prime}=1-\sqrt{(\gamma-1)^{2}+(\beta-1)^{2}+(\gamma-1)^{2}}
$$




$$
\begin{gathered}
\beta=\frac{\mu_{\mathrm{tar}}}{\mu_{\mathrm{ref}}} \\
\gamma=\frac{C V_{\mathrm{tar}}}{C V_{\mathrm{ref}}}=\frac{\sigma_{\mathrm{tar}} / \mu_{\mathrm{tar}}}{\sigma_{\mathrm{ref}} / \mu_{\mathrm{ref}}}
\end{gathered}
$$

where $r$ is the $C C$ between the reference (abbreviated as ref) and target (abbreviated as tar), $\beta$ is the bias ratio, $\gamma$ is the variability ratio, $\mu$ is the mean precipitation, $C V$ is the coefficient of variation, and $\sigma$ is the standard deviation of precipitation. KGE ranges from negative infinity to 1 .

To evaluate the detection ability, three widely used metrics are employed. They are (1) the probability of detection (POD), measuring the ability of satellite data to accurately capture actual precipitation events-the larger the value, the better the detection performance, with an optimal value of 1 ; (2) the false alarm rate (FAR), measuring the false alarm of satellite data on precipitation events- the smaller the value, the better the performance, with an optimal value of 0 ; and (3) critical success index (CSI), which is a function of $P O D$ and FAR with an optimal value of 1 . Their formulas are as follows:

$$
\begin{gathered}
P O D=\frac{O}{O+U} \\
F A R=\frac{P}{O+P} \\
C S I=\frac{O \quad}{O+U+P}=\frac{1}{1 /(1-F A R)+1 / P O D-1}
\end{gathered}
$$

where $O$ is the number of hit events where precipitation is detected by both the reference data set and the target data set, $U$ is the number of missed events where precipitation is detected by the reference data set but not by the target data set, and $P$ is the number of false alarms opposite to $U$.

\subsubsection{Identification of 3D Extreme Precipitation Events}

The 3D precipitation events refer to continuous precipitation grids in a three-dimensional space (i.e., latitude, longitude, and time), which can display the temporal and spatial motion information. The object-tracking method proposed by Zhou et al. is used to extract 3D extreme precipitation events [44]. This method assumes that the extreme precipitation event has multiple discrete (local) extreme units in time and space and a precipitation grid surrounding these units. Grids with rainfall intensity greater than $0.01 \mathrm{~mm} / \mathrm{h}$ are included. The basic philosophy is to use the mean and standard deviation of the precipitation data in each pixel to define thresholds for extreme precipitation, thereby extracting events that are continuous in space and time. Moreover, an extreme event considers the evolution of precipitation, meaning that it includes different precipitation intensities corresponding to different stages of a storm. This, in turn, improves the accuracy of identifying extreme precipitation events, thereby providing new insight into the performance of satellite precipitation products.

The first step of this method is to determine the extreme precipitation threshold $R_{c}$ of each rainfall grid (see Equation (9)). All grids with precipitation larger than $R_{c}$ are treated as extreme grids to form an extreme inventory. Then, starting from the extreme grid with the largest precipitation in the inventory, the tracking method recursively searches adjacent extreme grids within a certain spatiotemporal distance to form an extreme event. Please refer to [44] for a more detailed description. This step is repeated until all extreme grids in the inventory are classified to various extreme events. An experiment in the United States shows that this method can successfully capture extreme events such as Hurricane Harvey using IMERG. The specific technical steps include (1) the calculation of the local extreme precipitation intensity threshold, (2) the construction of the extreme inventory, and (3) the spatiotemporal object-based method for extreme event extraction. We define the local extreme thresholds by averaging values for each precipitation grid separately and 
then add a certain multiple of the standard deviation to obtain the precipitation threshold. The calculation formula is described as follows:

$$
R_{c}(x, y)=Z(x, y)+2.5 \sigma(x, y)
$$

where, $R_{c}(x, y)$ is the local precipitation threshold at grid $(x, y)$ under arbitrarily given conditions, $Z$ and $\sigma$ are the average and standard deviation of the precipitation grid, respectively. Note that if the local threshold $R_{c}(x, y)$ is lower than $5 \mathrm{~mm} / \mathrm{h}$, the threshold is set to $5 \mathrm{~mm} / \mathrm{h}$ to avoid including too many light precipitation events. This method enables the identification of spatiotemporal storm characteristics (e.g., duration and propagation speed), which enhance our understanding of extreme precipitation events.

\section{Results and discussion}

\subsection{Evaluation Results at Multiple Scales \\ 3.1.1. Evaluation at the Hourly Scale}

Many applications are built on sub-daily precipitation data, and thus, hourly scale evaluation is critical to comprehensively understand the accuracy of IMERG. Figure 3 shows the spatial distributions of the three-evaluation metrics, $C C, M E$, and $\mathrm{KGE}$, for the two IMERG products at the hourly scale. The $C C$ is below 0.2 . $M E$ is relatively small in most areas of the North China Plain and is characterized by alternating positive and negative values. KGE balances the contributions of correlation, deviation, and variability. KGE values are very low (all below 0.1 ) for both IMERG-L and IMERG-F. All three evaluation metrics show that the accuracy of the two IMERG products at the hourly scale is quite poor compared to the rain gauge measurements. The difference between IMERG-F and IMERG-L is not obvious, indicating that the monthly correction used for IMERG-F has little impact on the hourly scale data. However, the current deviation correction of IMERG forces IMERG's monthly precipitation to be consistent with the Global Precipitation Climatic Center (GPCC). This method has two limitations: (1) the spatial resolution of GPCC is coarse, and thus, the correction cannot account for the spatial variability of IMERG precipitation at the 0.1-degree resolution; and (2) the monthly correction only adjusts the total precipitation amount but cannot adjust sub-monthly (e.g., daily and hourly) precipitation temporal variability. This limitation restricts the further improvement of the quality of IMERG-F. Therefore, a possible future solution is to use a high-resolution meter-based daily precipitation data set to correct IMERG satellite precipitation estimates. IMERG should consider adopting bias correlation or calibration with ground measurements at finer temporal resolutions (daily or even hourly scale) in future versions.

Figure 4 shows the distribution of the detection ability of the two products at the hourly scale in terms of POD, FAR, and CSI. Again, the detection ability of IMERG-F is similar to that of IMERG-L. The maximum values of POD and CSI are 0.4 and 0.2 , respectively, while the minimum FAR is 0.6. Obviously, the two products have low detection ability. However, it should be noted that for hourly scale evaluation, some problems such as the continuity time and the mismatch between point scale rain gauges and regional satellite data may lead to greater uncertainty.

\subsubsection{Evaluation at the Daily Scale}

The evaluation of daily precipitation is performed with rain gauge measurements from 2000 to 2018. Figure 4 presents the distributions of three metrics: CC, ME, and KGE. Combining the results of various indicators, the performance of the southern region is higher than that of the northern region, and IMERG-F is slightly better than the IMERG-L in statistical accuracy. CC and KGE of IMERG-F are significantly higher than that of IMERG$\mathrm{L}$, while the magnitude of ME is smaller. In all, IMERG-L significantly overestimates precipitation, while IMERG-F solves this problem due to monthly bias correction.

Combined with the results in Figure 5, both IMERG-F and IMERG-L can better detect precipitation in the southern region. Figure 6 shows the distribution of POD, FAR, and CSI. 
Notably, the difference between MERG-F and IMERG-L is extremely small, resulting in similar colors in Figure 5. This proves that the monthly scale correction of IMERG-F has little impact on daily scale precipitation's occurrence. Meanwhile, in the northeast part of the study area, the FAR of IMERG-F is slightly smaller than that of IMERG-L, indicating that IMERG-F has a lower false alarm rate and relatively better accuracy.

(a) IMERG-F: CC

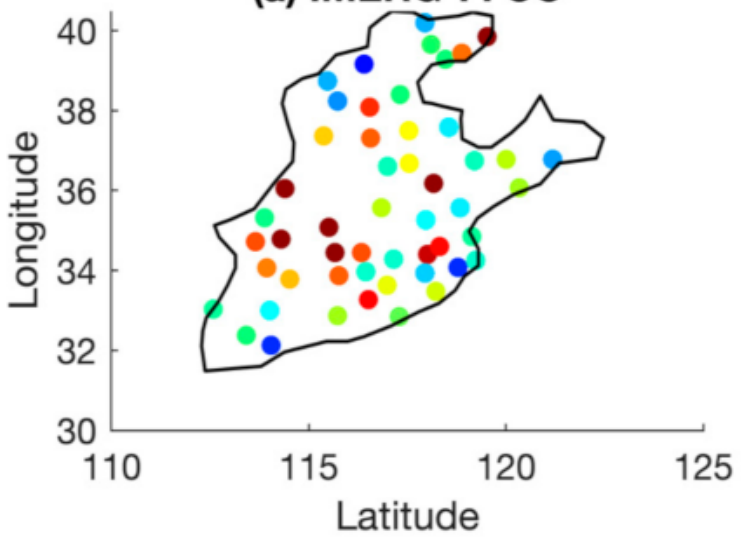

(c) IMERG-F: ME

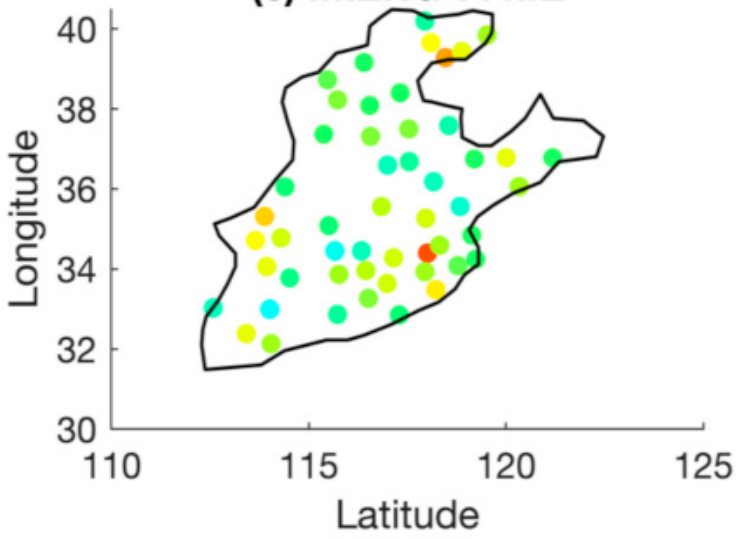

(e) IMERG-F: KGE

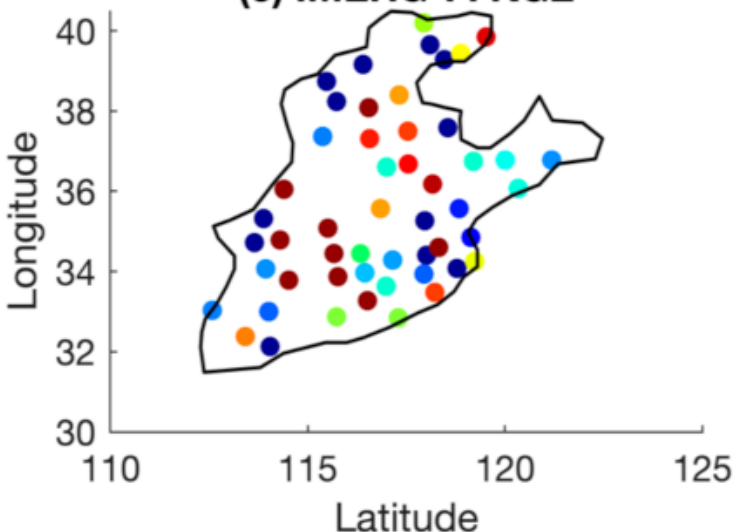

(b) IMERG-L: CC

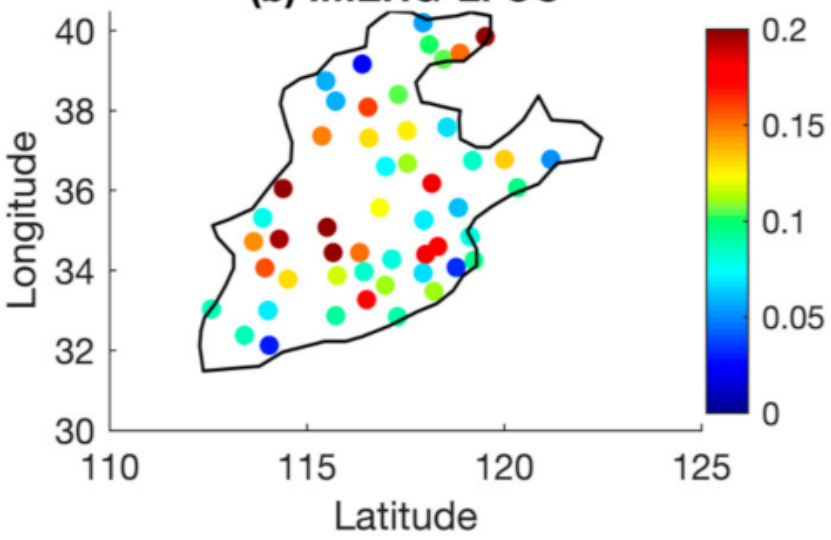

(d) IMERG-L: ME

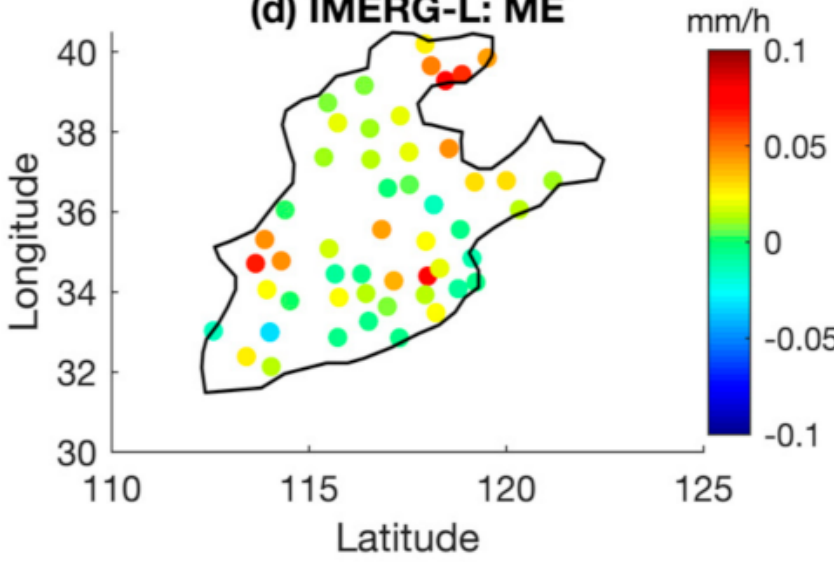

(f) IMERG-L: KGE

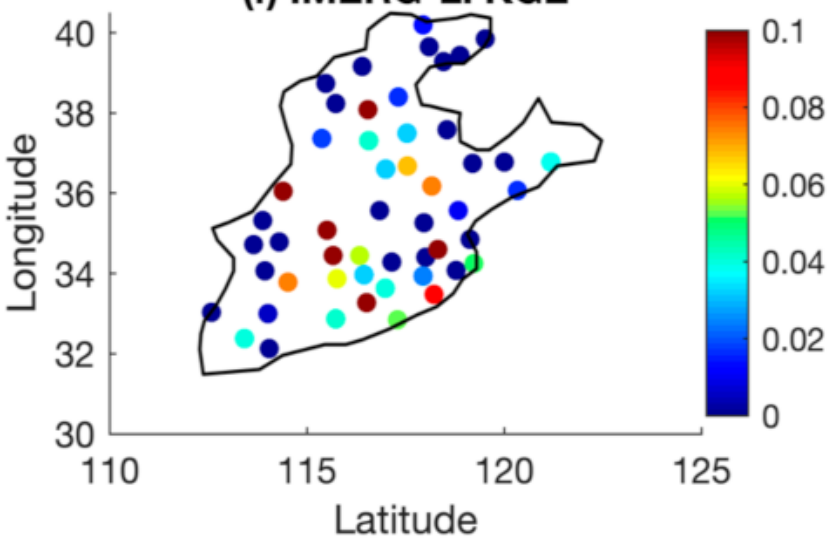

Figure 3. The distributions of CC, ME, and KGE for the IMERG-F and IMERG-L precipitation products at the hourly scale. 

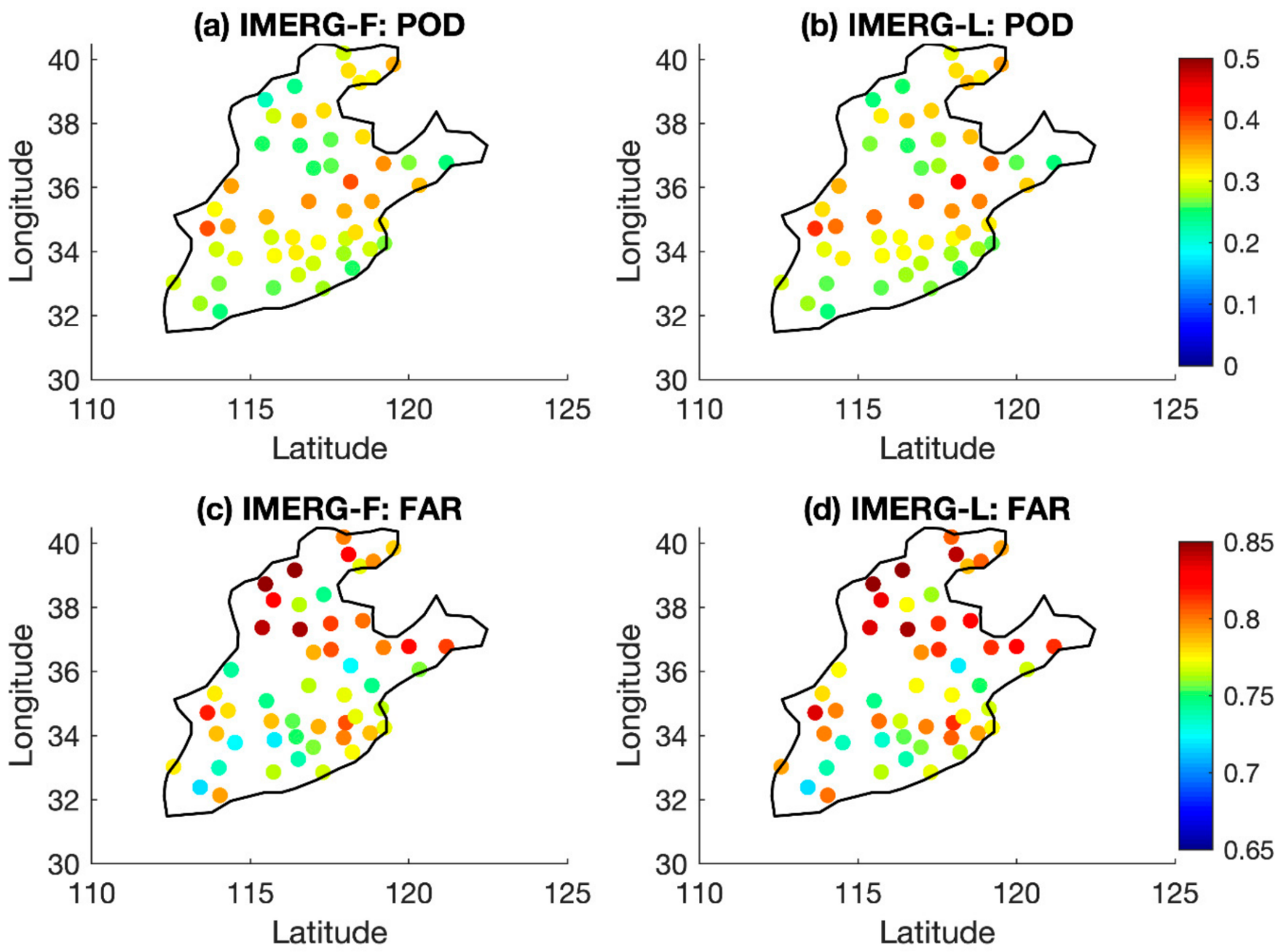

(e) IMERG-F: CSI
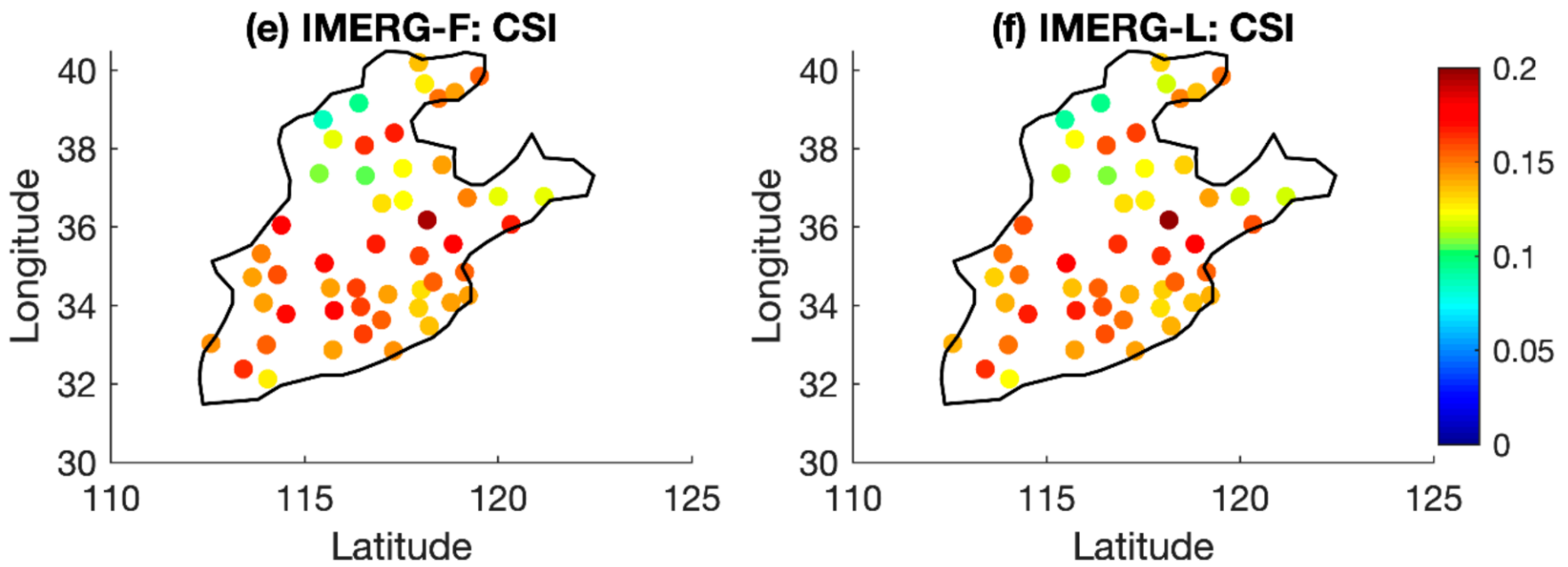

Figure 4. The distributions of POD, FAR, and CSI for the IMERG-F and IMERG-L precipitation products at the hourly scale. 

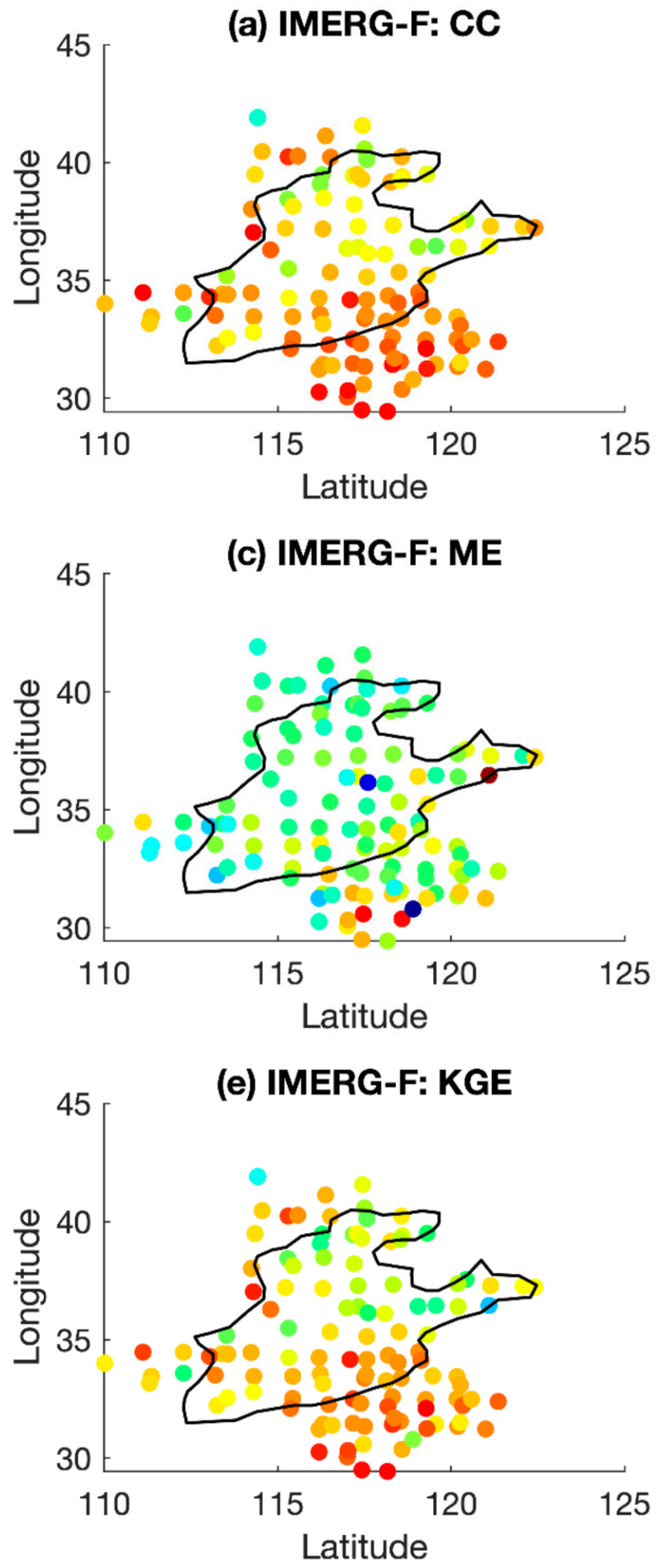

(b) IMERG-L: CC
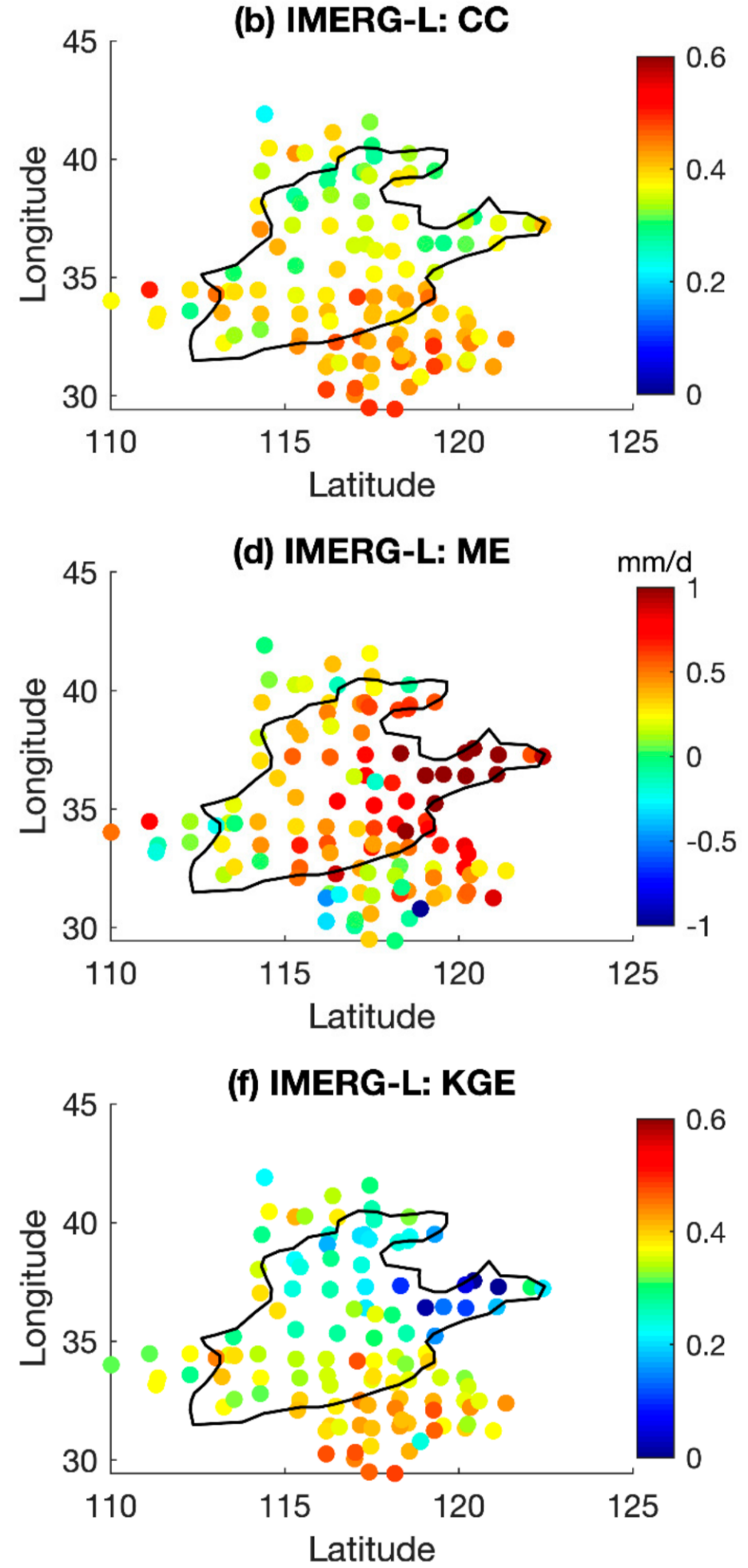

Figure 5. The distributions of three metrics $C C, M E$, and KGE for the IMERG-F and IMERG-L precipitation products at the daily scale. 

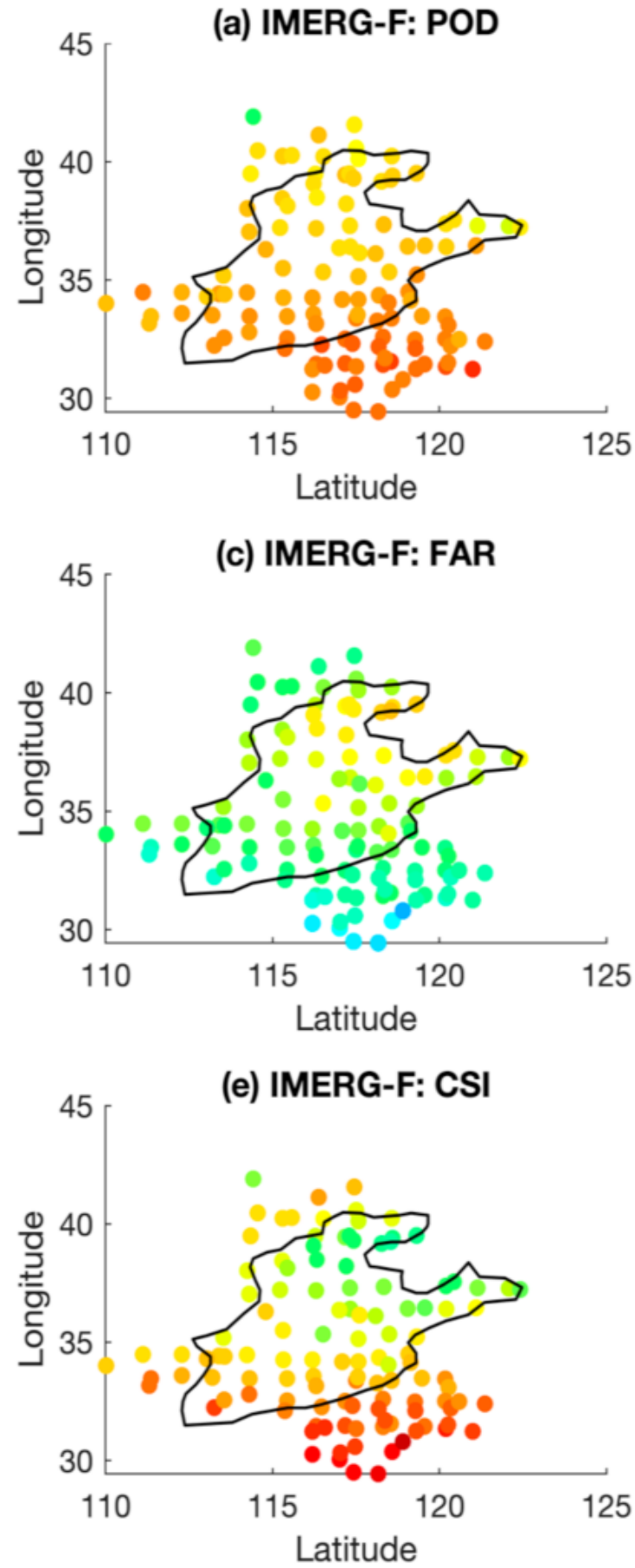

(b) IMERG-L: POD
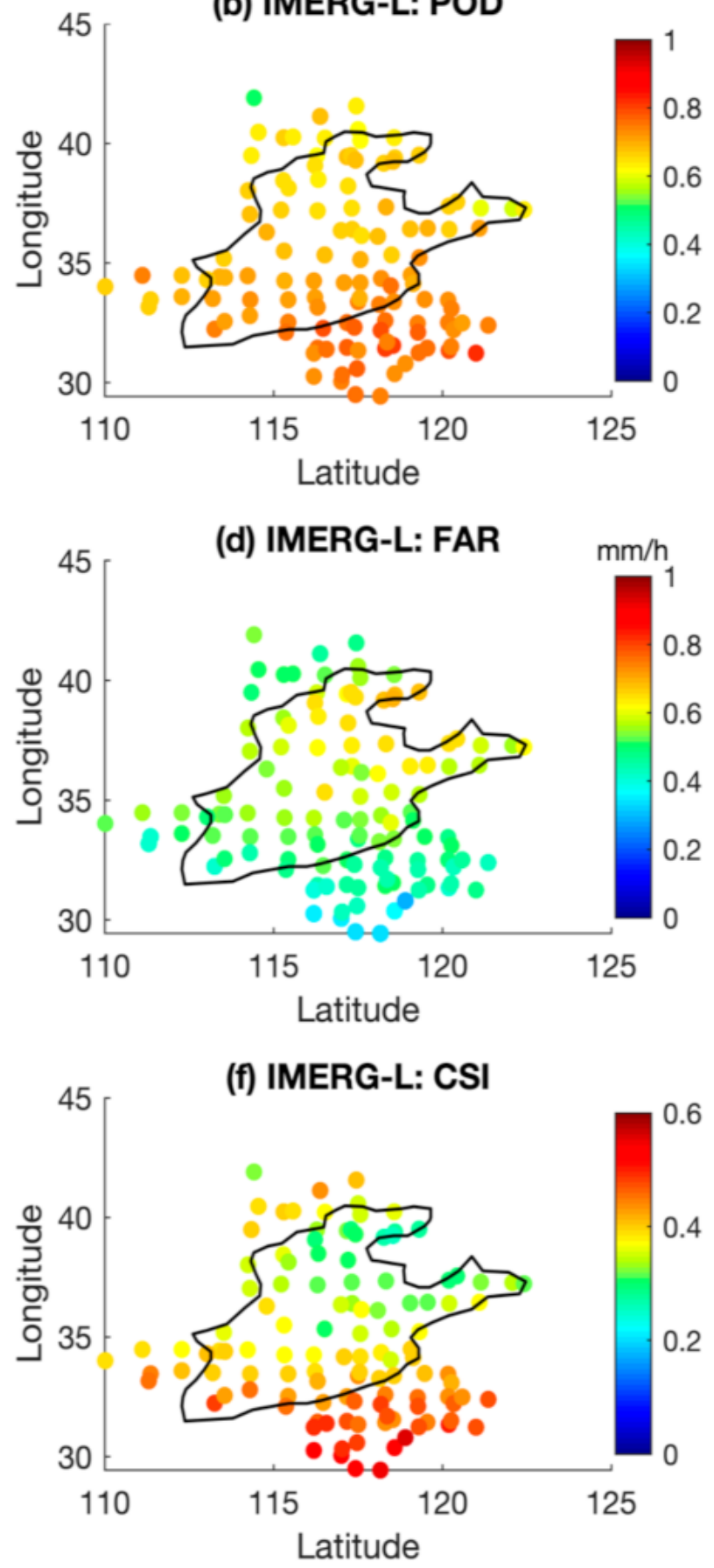

Figure 6. The distributions of three metrics POD, FAR, and CSI for the IMERG-F and IMERG-L precipitation products at the daily scale.

\subsubsection{Evaluation Results at the Seasonal Scale}

The seasonal analysis is conducted by calculating the indicators of daily or hourly data in the corresponding season and then analyzing it by season. Figure 7 is the box plot of CC, KGE, and CSI for IMERG-F and IMERG-L products. Among them, the horizontal line inside the box is the median, the upper and lower boundaries of the box are $25 \%$ and $75 \%$ of the data, and the two outermost horizontal lines represent $10 \%$ and $90 \%$ of the data. Overall, the seasonal assessment indicators of IMERG-F and IMERG-L have insignificant differences. For example, the IMERG-F box type is higher than that of IMERG-L, and the numerical value and the median value vary widely. 


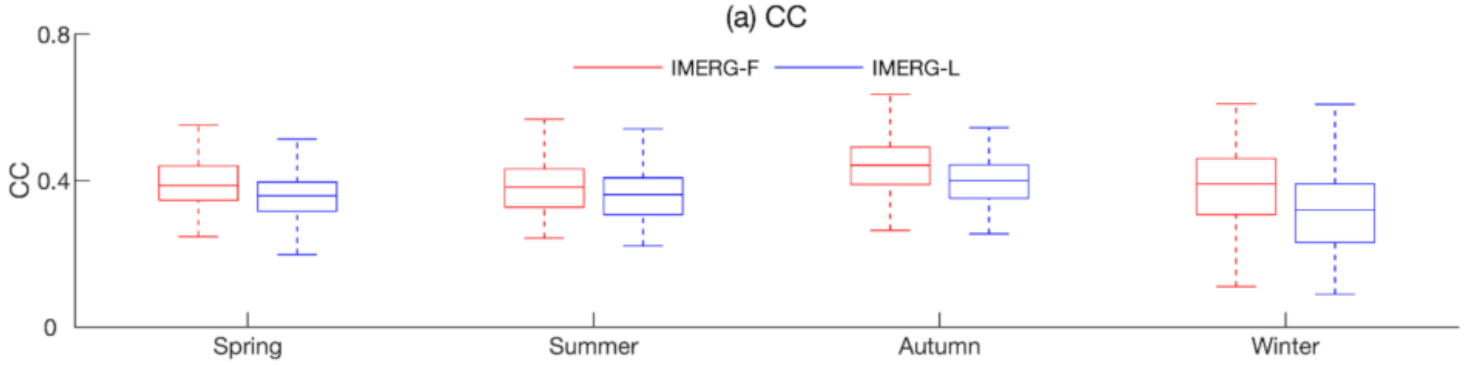

(b) KGE

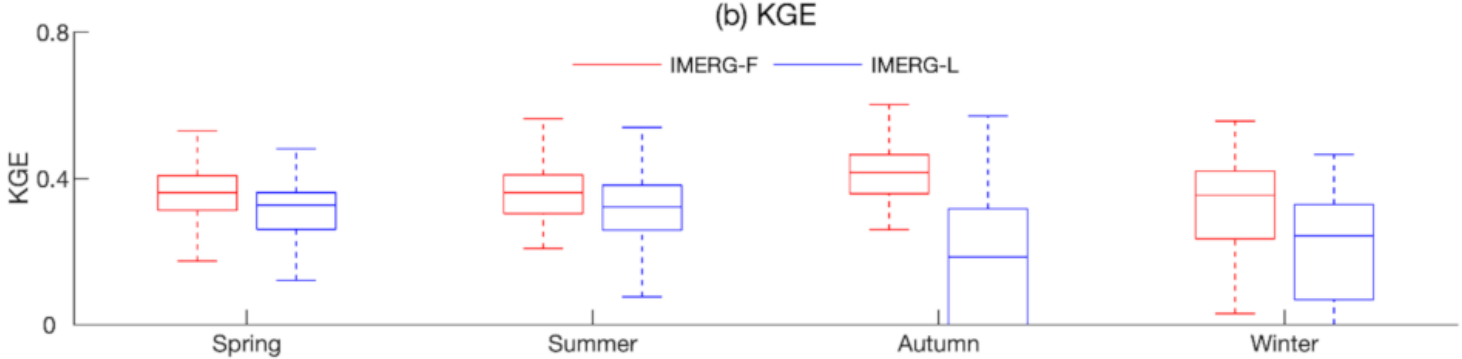

(c) CSI
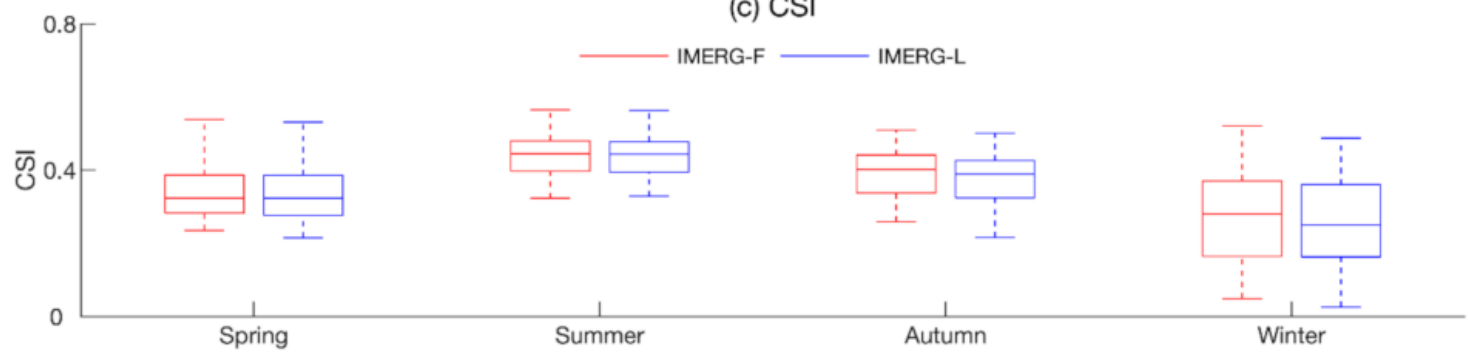

Figure 7. The distributions of three metrics CC, KGE, and CSI for the IMERG-F and IMERG-L precipitation products at the seasonal scale.

Combined with the correlation indicators in Figure 7a, the CCs of IMERG-F in spring, summer, autumn, and winter are $0.39,0.38,0.44$, and 0.38 , respectively, which are higher than the corresponding $0.35,0.36,0.4$, and 0.31 of IMERG-L. The winter box width ratio is higher than that of the other three seasons, which is related to the climate of the North China Plain. Meanwhile, the KGEs of IMERG-F in spring, summer, autumn, and winter are $0.36,0.36,0.41$, and 0.32 , respectively, which are higher than the corresponding 0.31 , $0.31,0.08$, and 0.17 of IMERG-L. In short, the regional performance of winter precipitation is unstable and changes greatly (Figure $7 \mathrm{~b}$ ). However, the cabinets of IMERG-L vary widely, even below 0 , reflecting the poor quality of the products in autumn and winter. For IMERG-F, the improvement effect is very obvious in autumn and winter but not obvious in summer when there is more precipitation. The CSI index characterizes the ability of these two products to detect precipitation. The CSIs of IMERG-F in spring, summer, autumn, and winter are $0.34,0.44,0.39$, and 0.27 , respectively, higher than the corresponding $0.34,0.44$, 0.37 , and 0.26 of IMERG-L. The accuracy is similar in spring and summer, while in winter and spring, IMERG-F is slightly better than IMERG-L (Figure 7c). In all, IMERG-F is better than IMERG-L on the seasonal scale. Among them, there is little difference in summer with more precipitation, and the regional performance is relatively stable, while in winter, the regional performance of precipitation is unstable and has greater variability.

\subsection{Evaluation in Terms of 3D Extreme Precipitation Events}

Three-dimensional precipitation events are extracted using the object-tracking method. Figure 8 shows the thresholds of extreme precipitation for IMERG-F and IMERG-L at the hourly and daily scales. The thresholds display strong spatial variation, gradually 
decreasing from ocean to inland. This is because the water vapor supply in the inland areas is less than in the ocean and coastal areas, and thus, the intensity is lower. The lower thresholds of the IMERG-F indicate that performing bias correction with gauge data results in lower precipitation intensity. IMERG-L thresholds have a smooth transition between the ocean and the land, which conforms to the actual evolution of precipitation systems. However, IMERG-F thresholds drop sharply from ocean to land (Figure $7 \mathrm{~b}$ ). The main reason is that rain gauge data used for bias correction during the generation of the IMERG-F are mainly from land, excluding measurements from the ocean (mainly due to the limited availability of data). Therefore, the bias correction would inevitably lead to more bias for the transitional areas between the ocean and land. In contrast, IMERG-F and IMERG-L data products are similar on the ocean. Therefore, if IMERG-F is applied to study typhoon and hurricane phenomena generated over the ocean and propagated to land, data users must consider the discontinuity caused by this problem.
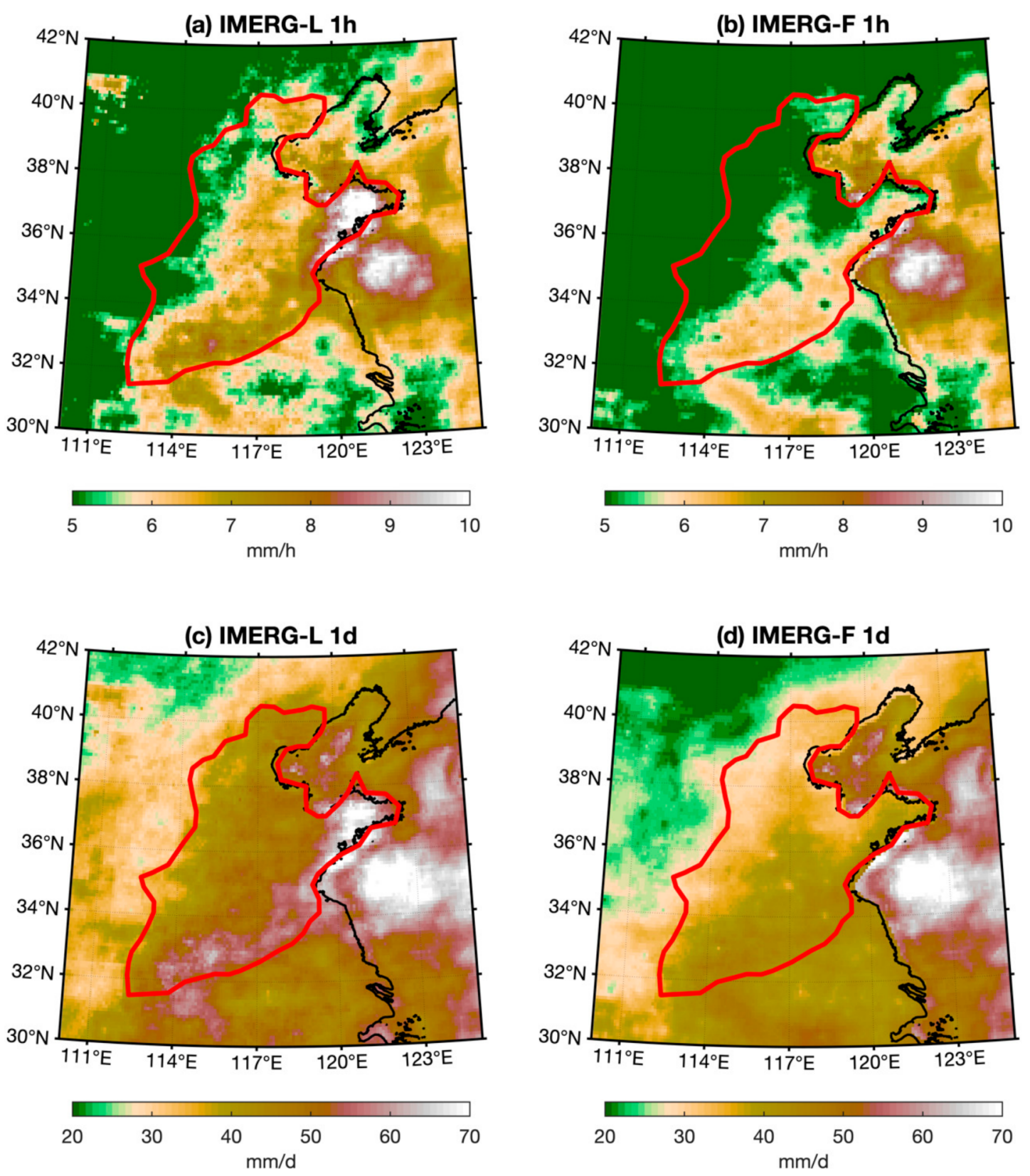

Figure 8. Threshold for extracting hourly $(\mathbf{a}, \mathbf{b})$ and daily $(\mathbf{c}, \mathbf{d})$ extreme precipitation events from 2000 to 2018 . 
In this study, we extract three-dimensional precipitation systems, which include the generation, movement, and dissipation processes of a precipitation system. For example, a precipitation event may occur over the ocean and move to land with time. Figure 9 reveals the seasonal characteristics of extreme precipitation events (duration, total pixels, maximum rainfall, and average rainfall intensity). The precipitation area is defined as the number of total pixels of a precipitation event. Maximum precipitation is defined as the maximum precipitation measured or investigated in a certain period and area. IMERG-L presents a longer event duration than IMERG-F for all seasons except summer. IMERG-F displays the longest precipitation duration in summer, while IMERG-L has less obvious seasonal variations. Figure $9 \mathrm{~b}$ reveals that the precipitation coverage of the four seasons is basically the same, but IMERG-L is higher than IMERG-F.
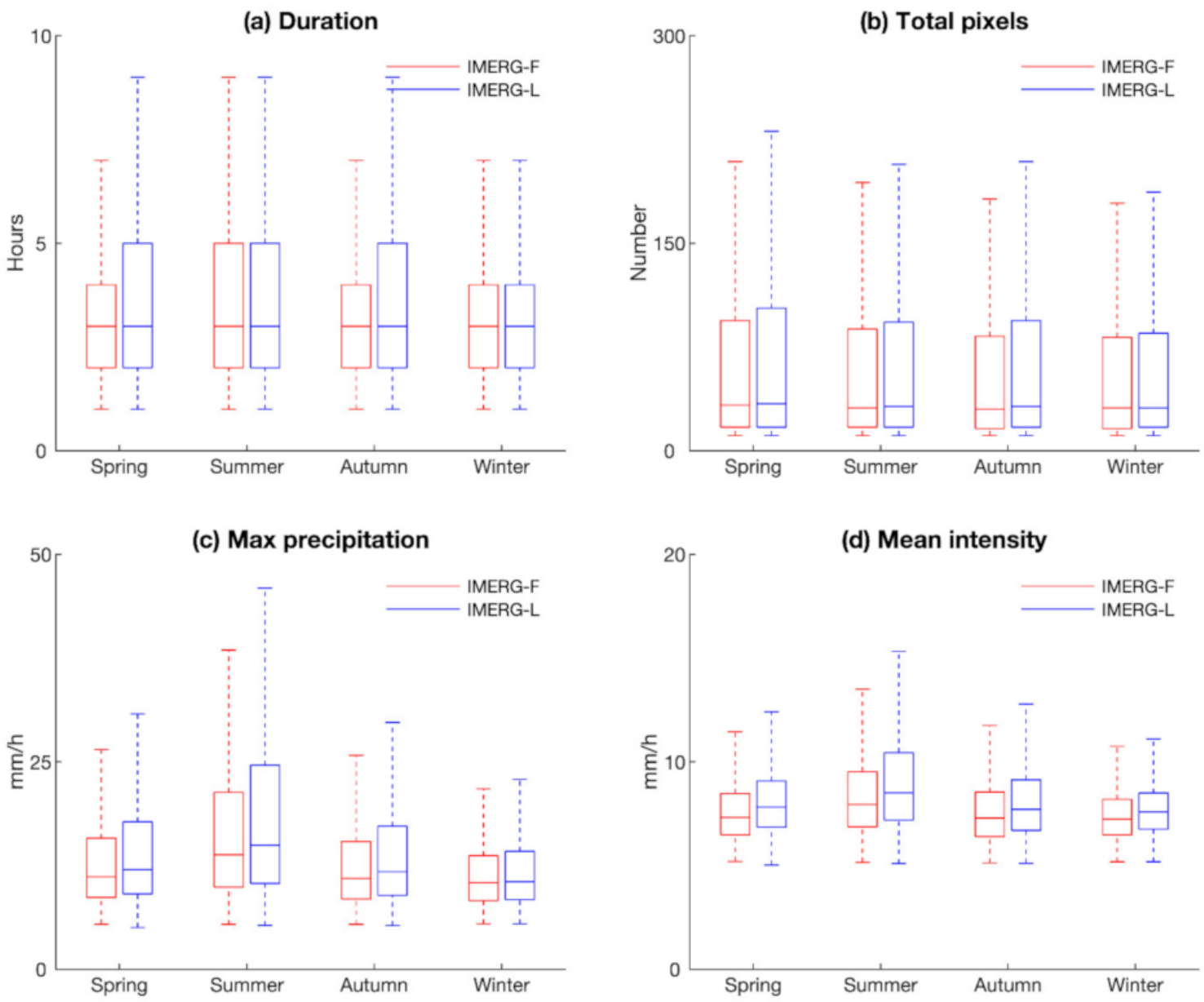

Figure 9. Features of hourly scale extreme precipitation events from 2000 to 2018.

The maximum precipitation refers to the maximum intensity of every three-dimensional event (Figure 9c). The maximum precipitation has notable seasonal variation and reaches the peak in summer. Moreover, the maximum precipitation of IMERG-L exceeds that of IMERG-F. Compared to the maximum intensity, the mean intensity has similar seasonal features but a much smaller magnitude (Figure 9d). The monthly gauge-based correction used by IMERG-F can adjust the amount of precipitation, as revealed by many previous studies [10]. However, our analysis shows that the correction can impact the whole lifecycle of precipitation systems, such as the duration and affected area in Figure 9. This adjustment indirectly contributes to the reduction of precipitation overestimation in the North China Plain (Figure 5).

Figures 10 and 11 evaluate the extreme precipitation of IMERG and compare IMERG to PERSIANN-CCS and GSMAP using rain gauge data at hourly and daily scales. CC and 
BIAS of each 3-D precipitation event are selected as the metrics that follow. The hourly median CCs of IMERG-F, IMERG-L, GSMaP, and PERSIANN-CCS are $-0.2,-0.16,-0.09$, and 0.06 , respectively. IMERG-F, IMERG-L, and GSMaP have negative linear correlations, and IMERG-F has the best correlation. The median daily CCs of IMERG-F and IMERG-L are 0.31 and 0.3 , respectively. Both IMERG-F and IMERG-L have a positive correlation, but IMERG-F is slightly better than IMERG-L.
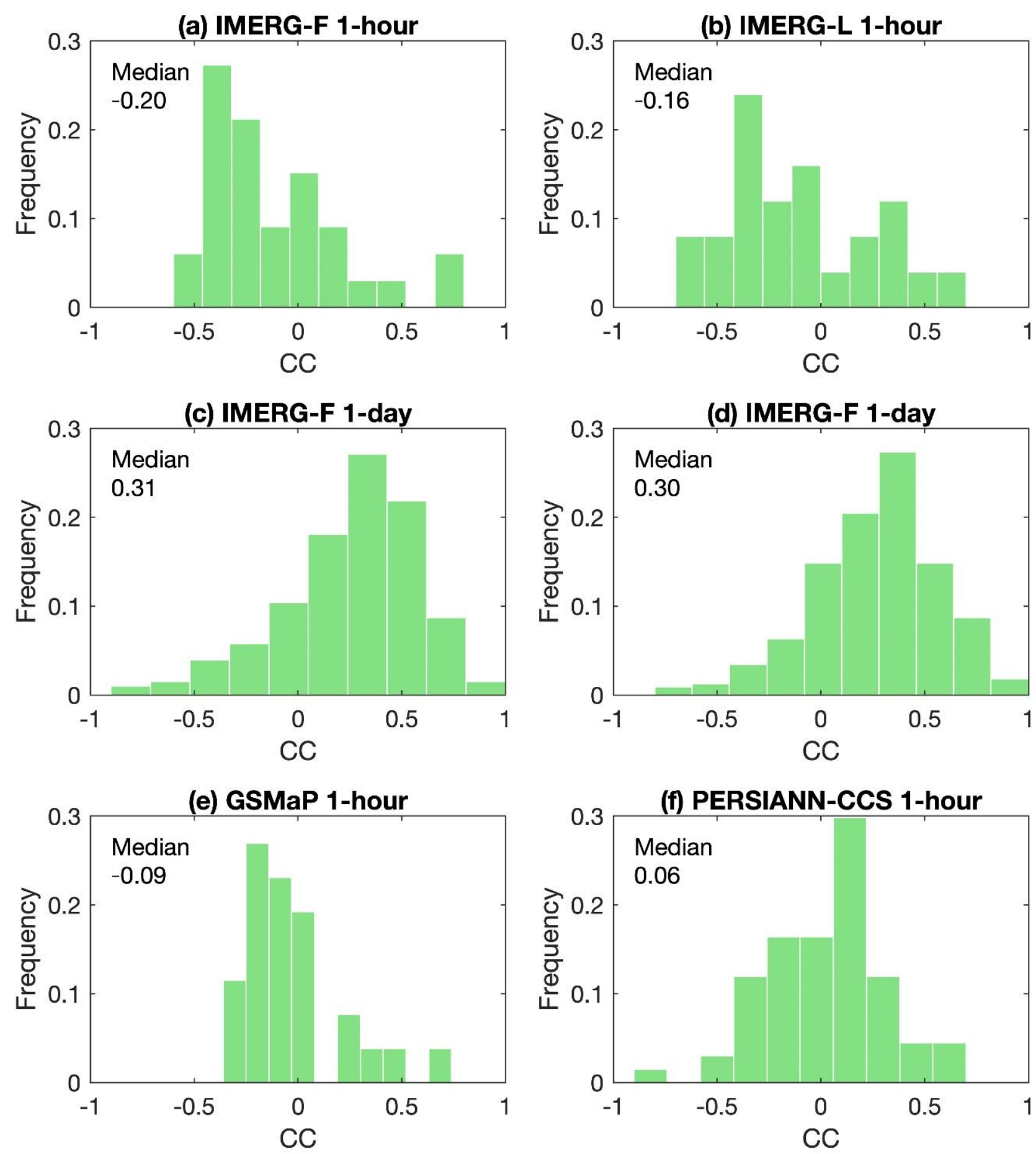

Figure 10. The CC of hourly and daily extreme precipitation from 2000 to 2018. 

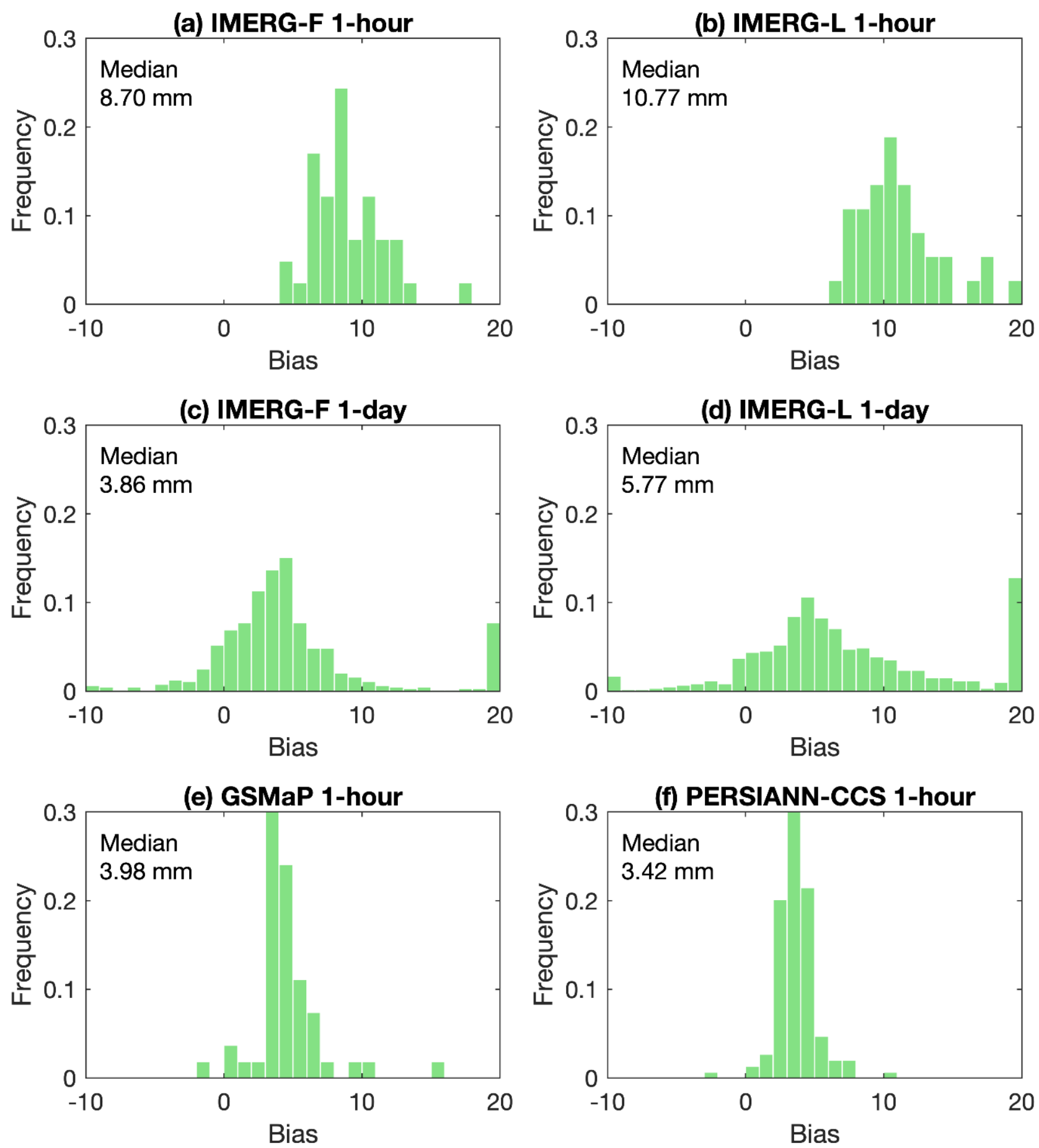

Figure 11. The Bias of hourly and daily extreme precipitation from 2000 to 2018.

In terms of the mean error, the median hourly BIAS of IMERG-F, IMERG-L, GSMaP, and PERSIANN-CCS are 8.7, 10.77, 3.98, and $3.42 \mathrm{~mm}$. Notably, both IMERG-F and IMERG-L overestimate precipitation. Among them, the relative error of IMERG-F is small: better than IMERG-L and slightly worse than GSMAP and PERSIANN-CCS. However, GSMaP and PERSIANN-CCS have a certain underestimation of precipitation. The median daily BIAS of IMERG-F and IMERG-L were 3.86 and 5.77. Similarly, IMERG-F was better than IMERG-L. 
Based on the above analysis, the mean error of IMERG-F is better than IMERG-L, but the $\mathrm{CC}$ is lower, which is consistent with the previous analysis. Although many studies have shown that the quality of PERSIANN-CCS is generally low, GSMAP and PERSIANN-CCS are better for extreme precipitation in the North China Plain, especially PERSIANN-CCS, which shows that infrared has potential for extreme precipitation.

\subsection{Extreme Precipitation-Induced Disaster Analysis}

Flash flood disasters are caused by heavy rainfall in hilly areas and can result in debris flow and landslides, causing considerable losses to the national economy and people's lives and property. The precursors of flash flood events are closely related to the intensity of precipitation, among which previous continuous rainfall and sudden heavy rainfall are the main causes of flash floods. It is extremely important to make short-term rainfall forecasts in advance, which is inseparable from high-precision rainfall data. Therefore, assessing the accuracy of IMERG to capture flash flood disasters is extremely important for flash flood early warnings in un-gauged basins. Combined with the better performance of IMERG-F, the article mainly focuses on qualitative analysis due to the difficulty of collecting large samples of measured flood data. Therefore, this study takes the " $7 \cdot 19$ " flood disaster as an example to investigate whether the spatial distribution of IMERG-F agrees with flood events.

Based on flash flood events, the danger is divided into four levels, as shown in Figure 11, where the vertical axis is the number of dead or missing - the greater the value, the greater the disaster intensity. Flash floods are concentrated in the lower levels (second and first), while the more serious third and fourth levels occur less frequently but cause more casualties. Figure 12 also demonstrates that the typical case selected in this article (the "7.19" flash flood disaster) is very harmful. If the satellite precipitation data can capture the precipitation that induced the disaster, this will greatly improve the accuracy of flash flood forecasting, thereby reducing the impact of the disaster.

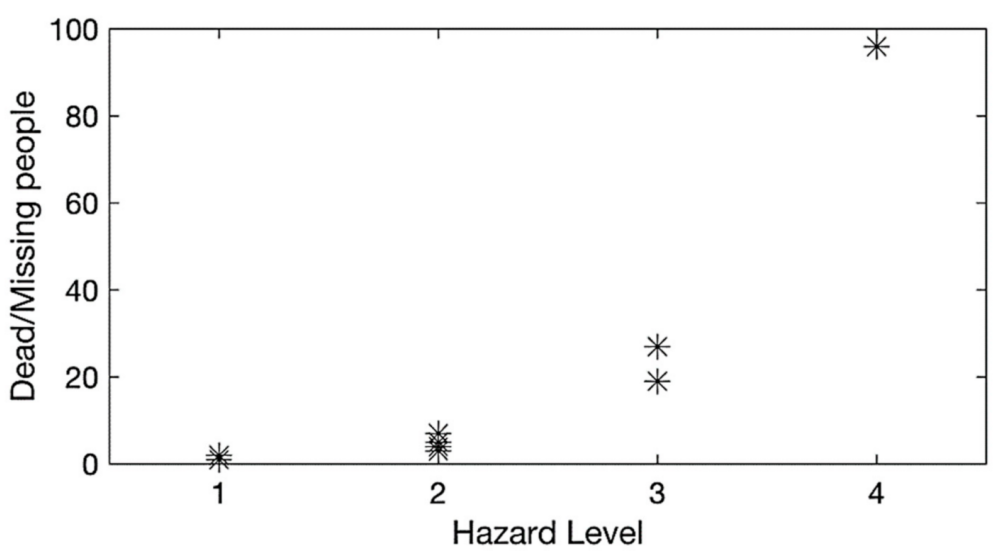

Figure 12. Levels of 14 flash flood hazard events $(*)$. A larger level means more severe events.

From 18 to 20 July 2016, the "7.19" flood occurred in Hebei Province, mainly due to heavy rainfall. Considering the impact of previous rainfall, this study uses the evolution of rainfall data to analyze the disaster probability captured by IMERG-F and IMERG-L from 15 to 23 July. Figure 13 shows the precipitation distribution from 15 to 23 July 2016, where (a) and (b) are IMERG-F and IMERG-L, respectively. The background is the precipitation of the corresponding IMERG product, and the black circles represent station precipitation, filled with the same color map of the corresponding IMERG product. The precipitation spatial distributions of IMERG-F and IMERG-L are basically consistent with the ground station and can capture the precipitation center. From 15 to $18 \mathrm{July}$, both of them captured most of the rainfall. From 18 to 21 July, these two precipitation products were in good agreement with the measured precipitation, reproducing the precipitation process. On 19 July, both IMERG and station data show relatively strong precipitation in the disaster 
area, indicating that heavy rainfall directly induced the disaster. On 20 July, the disaster-hit area had a small intraday rainfall and a large previous rainfall, reflecting that the previous cumulative rainfall was also a key factor inducing flood. On 21 to 23 July, the filling color of the small black circle was the same as the background color, again verifying that IMERG-F and IMERG-L were consistent with the measured precipitation. However, the area where the flood occurred on 23 July underwent heavy rainfall on 19 July, which may be attributed to different types of disasters that have not been confirmed in the previous period. Above all, both IMERG-F and IMERG-L have high accuracy in capturing disaster-inducing rainfall. Of course, the current flood research is relatively weak, especially in collecting measured disaster data. In the future, more flood disaster data needs to be collected to further strengthen the analysis.
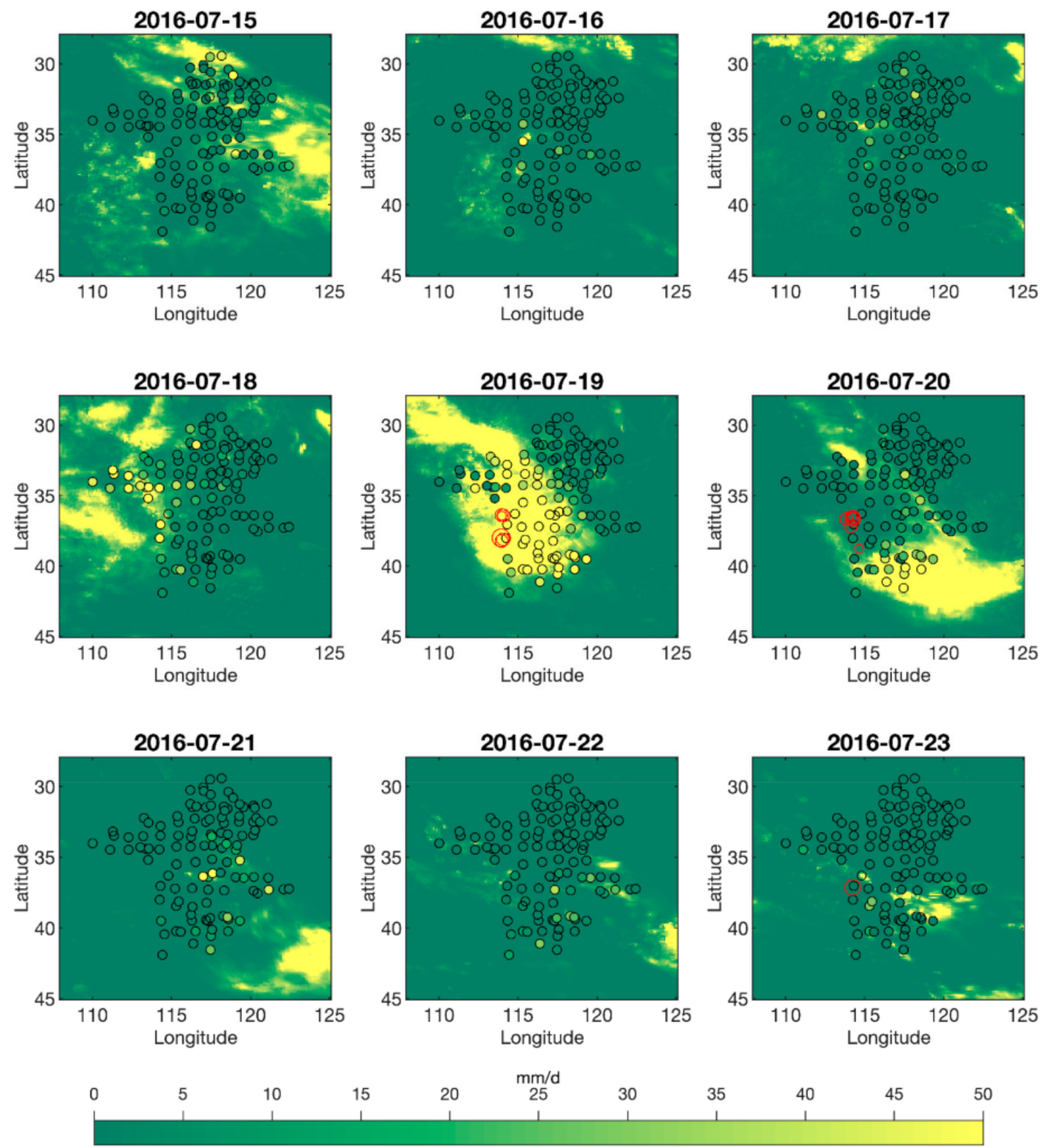

(a)

Figure 13. Cont. 

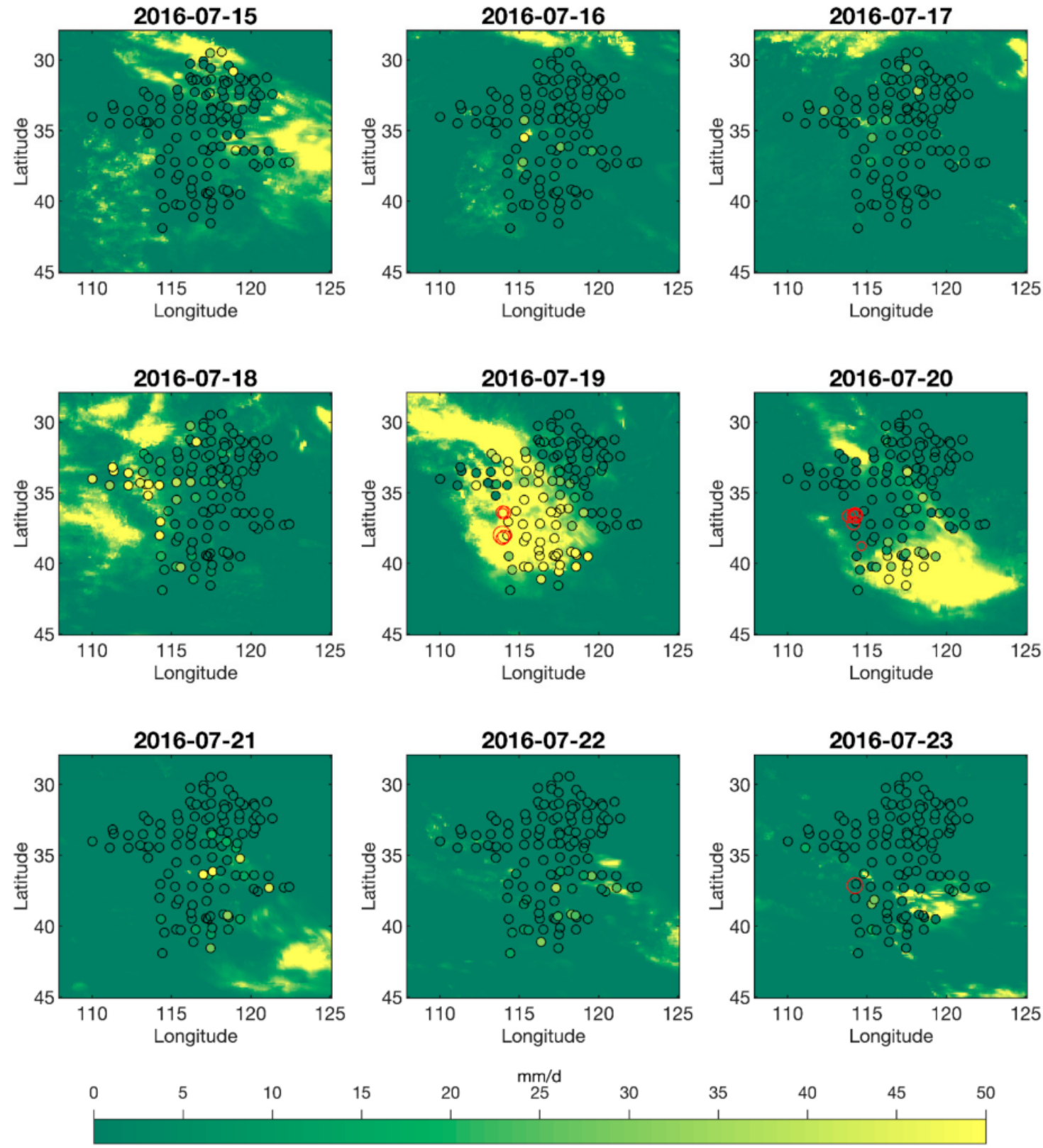

(b)

Figure 13. The distribution of precipitation and floods. The background is the precipitation of the corresponding IMERG products. The black, color filled dots are station observed precipitation. The red circles are flash flood events. (a) hazard_dailyP_cal, IMERG-F. (b) hazard_dailyP_uncal, IMERG-L.

\section{Conclusions}

This study evaluated the accuracy of the latest version of IMERG V06 satellite precipitation products (IMERG-L and IMERG-F) in capturing extreme precipitation at multiple scales and compared IMERG to several other datasets in the North China Plain. We utilized the novel object-based tracking method to extract 3D extreme precipitation events, which can comprehensively demonstrate the spatiotemporal evolution of precipitation systems compared to traditional evaluation methods. In addition, we selected a typical 
flood event in the North China Plain to explore whether IMERG can capture extreme precipitation-triggering floods.

The statistical evaluation shows that overall, IMERG-F is better than IMERG-L. The improvement is more notable for bias-related metrics such as mean error and KGE compared to CC and contingency metrics (POD, FAR, and CSI). However, the improvement is less significant at the hourly scale than the daily scale. This phenomenon is caused by the nature of the monthly scale total volume correction, which has a limited effect on adjusting daily variations of precipitation.

Object-based tracking is beneficial for more comprehensive evaluation. Although this study focuses on land areas, we found that IMERG-F exhibits discontinuity concerning the thresholds of extreme precipitation between land and ocean, while IMERG-L does not have this problem. This reminds researchers that caution is needed when using bias-corrected satellite products to study extreme precipitation in land-ocean transition zones. IMERG-L and IMERG-F show similar characteristics of extreme precipitation (e.g., seasonal variation) in the North China Plain. IMERG-F shows smaller precipitation duration, precipitating areas, and max and mean precipitation intensity, indicating that monthly correction reduces precipitation occurrence and magnitude in the study area. However, based on the evaluation metrics, both IMERG-L and IMERG-F do not outperform PERSIANN-CCS and GSMaP in capturing 3D extreme events at the hourly and daily scales. The IMERG products have a great deal of room for improvement, although qualitative flood assessment indicates that IMERG products can generally capture the precipitation events triggering floods.

In summary, this study validates that GPM IMERG can generally capture extreme precipitation in the North China Plain, whereas the quantitative estimates of extreme precipitation still have room for improvement according to statistical metrics. One limitation is the utilization of monthly scale correction, which cannot effectively adjust the daily variation of satellite precipitation. Future IMERG versions could consider adopting daily or sub-daily bias correction to further improve the performance of IMERG-F. Meanwhile, researchers should also pay attention to the discontinuity in coastal regions caused by gauge-based correction over land. This study shows that the object-based tracking method provides more evaluation aspects (e.g., precipitation features such as duration and max intensity and event-based evaluation) compared to pixel-by-pixel evaluation. Future studies could explore how multiple factors (e.g., regional distribution, wind direction, and terrain features) affect the errors revealed by object-based tracking methods and carry out more comprehensive multi-satellite dataset comparisons in broader regions. Finally, the general lack of flood disaster data limits relevant research. Thus, it is challenging but meaningful for future studies to collect and share more flood disaster data.

Author Contributions: Conceptualization, D.Z., M.M. and G.T.; data curation, D.Z., M.Y. and J.W.; formal analysis, S.M.; funding acquisition, D.Z. and X.Z.; investigation, M.M., T.W., X.Z., S.M., J.W. and W.W.; methodology, M.M. and G.T.; project administration, D.Z., M.Y., X.Z. and S.M.; resources, M.Y., X.Z. and S.M.; software, G.T. and J.W.; supervision, D.Z., M.Y., M.M. and G.T.; writing-original draft, M.M.; writing-review \& editing, D.Z. and G.T. All authors have read and agreed to the published version of the manuscript.

Funding: This research was funded by Dasheng Zhang grant number 19275403D, 2020-04, 13000021V8G4VKXBKLUMX; Meihong Ma grant number 42101086, Mingxiang Yang grant number U1865102, SKL2020TS01.

Institutional Review Board Statement: Not applicable.

Conflicts of Interest: The authors declare no conflict of interest. 


\section{References}

1. Skofronick-Jackson, G.; Petersen, W.A.; Berg, W.; Kidd, C.; Stocker, E.F.; Kirschbaum, D.; Kakar, R.; Braun, S.A.; Huffman, G.; Iguchi, T.; et al. The Global Precipitation Measurement (GPM) Mission for Science and Society. Bull. Am. Meteorol. Soc. 2017, 98, 1679-1695. [CrossRef] [PubMed]

2. Qiaohong, S.; Zhang, X.; Zwiers, F.W. A Global, Continental, and Regional Analysis of Changes in Extreme Precipitation. J. Clim. 2020, 34, 243-258.

3. Rodrigues, D.T.; Gonçalves, W.A.; Spyrides, M.H.C.; Silva, C.M.S.E.; De Souza, D.O. Spatial distribution of the level of return of extreme precipitation events in Northeast Brazil. Int. J. Clim. 2020, 40, 5098-5113. [CrossRef]

4. Zhou, Y.; Nelson, K.; Mohr, K.; Huffman, G.J.; Levy, R.; Grecu, M. A Spatial-Temporal Extreme Precipitation Database from GPM IMERG. J. Geophys. Res. Atmos. 2019, 124, 10344-10363. [CrossRef]

5. Yang, Z.; Hsu, K.; Sorooshian, S.; Xu, X.; Braithwaite, D.; Zhang, Y.; Verbist, K.M.J. Merging high-resolution satellite-based precipitation fields and point-scale rain gauge measurements-A case study in Chile. J. Geophys. Res. Atmos. 2017, 122, 5267-5284. [CrossRef]

6. Abdourahamane, Z.S. Evaluation of fine resolution gridded rainfall datasets over a dense network of rain gauges in Niger. Atmos. Res. 2021, 252, 105459. [CrossRef]

7. Tang, G.; Clark, M.P.; Newman, A.J.; Wood, A.W.; Papalexiou, S.M.; Vionnet, V.; Whitfield, P.H. SCDNA: A serially complete precipitation and temperature dataset for North America from 1979 to 2018. Earth Syst. Sci. Data 2020, 12, 2381-2409. [CrossRef]

8. Tang, G.; Ma, Y.; Long, D.; Zhong, L.; Hong, Y. Evaluation of GPM Day-1 IMERG and TMPA Version-7 legacy products over Mainland China at multiple spatiotemporal scales. J. Hydrol. 2016, 533, 152-167. [CrossRef]

9. Agel, L.; Barlow, M.; Qian, J.-H.; Colby, F.; Douglas, E.; Eichler, T. Climatology of Daily Precipitation and Extreme Precipitation Events in the Northeast United States. J. Hydrometeorol. 2015, 16, 2537-2557. [CrossRef]

10. Tang, G.; Clark, M.P.; Papalexiou, S.M.; Ma, Z.; Hong, Y. Have satellite precipitation products improved over last two decades? A comprehensive comparison of GPM IMERG with nine satellite and reanalysis datasets. Remote Sens. Environ. 2020, $240,111697$. [CrossRef]

11. Mahmoud, M.T.; Al-Zahrani, M.A.; Sharif, H. Assessment of global precipitation measurement satellite products over Saudi Arabia. J. Hydrol. 2018, 559, 1-12. [CrossRef]

12. Prakash, S.; Mitra, A.K.; Pai, D.S.; AghaKouchak, A. From TRMM to GPM: How well can heavy rainfall be detected from space? Adv. Water Resour. 2016, 88, 1-7. [CrossRef]

13. Su, J.; Lü, H.; Crow, W.T.; Zhu, Y.; Cui, Y. The Effect of Spatiotemporal Resolution Degradation on the Accuracy of IMERG Products over the Huai River Basin. J. Hydrometeorol. 2020, 21, 1073-1088. [CrossRef]

14. Tang, G.; Zeng, Z.; Long, D. Statistical and Hydrological Comparisons between TRMM and GPM Level-3 Products over a Mid-latitude Basin: Is Day-1 IMERG a Good Successor for TMPA 3B42V7. J. Hydrometeorol. 2015, 17, 121-137. [CrossRef]

15. Liu, Z. Comparison of Integrated Multisatellite Retrievals for GPM (IMERG) and TRMM Multisatellite Precipitation Analysis (TMPA) Monthly Precipitation Products: Initial Results. J. Hydrometeorol. 2016, 17, 777-790. [CrossRef]

16. Xu, R.; Tian, F.; Yang, L.; Hu, H.; Lu, H.; Hou, A. Ground validation of GPM IMERG and TRMM 3B42V7 rainfall products over southern Tibetan Plateau based on a high-density rain gauge network. J. Geophys. Res. Atmos. 2017, 122, 910-924. [CrossRef]

17. Ostrenga, D.; Liu, Z.; Vollmer, B.; Teng, W.L.; Kempler, S.J. Global Precipitation Measurement (GPM) Mission Products and Services at the NASA Goddard Earth Sciences (GES) Data and Information Services Center (DISC). Bull. Am. Meteorol. Soc. 2016. [CrossRef]

18. Anjum, M.N.; Ding, Y.; Shangguan, D.; Ahmad, I.; Ijaz, M.W.; Farid, H.U.; Yagoub, Y.E.; Zaman, M.; Adnan, M. Performance evaluation of latest integrated multi-satellite retrievals for Global Precipitation Measurement (IMERG) over the northern highlands of Pakistan. Atmos. Res. 2018, 205, 134-146. [CrossRef]

19. Li, N.; Tang, G.; Zhao, P.; Hong, Y.; Gou, Y.; Yang, K. Statistical assessment and hydrological utility of the latest multi-satellite precipitation analysis IMERG in Ganjiang River basin. Atmos. Res. 2017, 183, 212-223. [CrossRef]

20. Ramadhan, R.; Marzuki, M.; Yusnaini, H.; Muharsyah, R.; Suryanto, W.; Sholihun, S.; Vonnisa, M.; Battaglia, A.; Hashiguchi, H. Capability of GPM IMERG Products for Extreme Precipitation Analysis over the Indonesian Maritime Continent. Remote Sens. 2022, 14, 412. [CrossRef]

21. Xia, X.; Fu, D.; Fei, Y.; Shao, W.; Xia, X. An Improved Assessment Method and Its Application to the Latest IMERG Rainfall Product in Mainland China. Remote Sens. 2021, 13, 5107. [CrossRef]

22. Prakash, S.; Srinivasan, J. A Comprehensive Evaluation of Near-Real-Time and Research Products of IMERG Precipitation over India for the Southwest Monsoon Period. Remote Sens. 2021, 13, 3676. [CrossRef]

23. Arabzadeh, A.; Behrangi, A. Investigating Various Products of IMERG for Precipitation Retrieval over Surfaces with and without Snow and Ice Cover. Remote Sens. 2021, 13, 2726. [CrossRef]

24. Maghsood, F.F.; Hashemi, H.; Hosseini, S.H.; Berndtsson, R. Ground Validation of GPM IMERG Precipitation Products over Iran Remote Sens. 2019, 12, 48. [CrossRef]

25. Navarro, A.; García-Ortega, E.; Merino, A.; Sánchez, J.L.; Kummerow, C.; Tapiador, F.J. Assessment of IMERG Precipitation Estimates over Europe. Remote Sens. 2019, 11, 2470. [CrossRef]

26. Watters, D.; Battaglia, A. The Summertime Diurnal Cycle of Precipitation Derived from IMERG. Remote Sens. 2019, 11, 1781. [CrossRef] 
27. Li, X.; Sungmin, O.; Wang, N.; Liu, L.; Huang, Y. Evaluation of the GPM IMERG V06 products for light rain over Mainland China. Atmos. Res. 2021, 253, 105510. [CrossRef]

28. Yang, M.; Liu, G.; Chen, T.; Chen, Y.; Xia, C. Evaluation of GPM IMERG precipitation products with the point rain gauge records over Sichuan, China. Atmos. Res. 2020, 246, 105101. [CrossRef]

29. Guo, H.; Chen, S.; Bao, A.; Behrangi, A.; Hong, Y.; Ndayisaba, F.; Hu, J.; Stepanian, P.M. Early assessment of Integrated Multi-satellite Retrievals for Global Precipitation Measurement over China. Atmos. Res. 2016, 176, 121-133. [CrossRef]

30. Chen, F.; Li, X. Evaluation of IMERG and TRMM 3B43 Monthly Precipitation Products over Mainland China. Remote Sens. 2016, 8 , 472. [CrossRef]

31. Zhao, H.; Yang, S.; You, S.; Huang, Y.; Wang, Q.; Zhou, Q. Comprehensive Evaluation of Two Successive V3 and V4 IMERG Final Run Precipitation Products over Mainland China. Remote Sens. 2018, 10, 34. [CrossRef]

32. Wang, D.; Wang, X.; Liu, L.; Wang, D.; Huang, H.; Pan, C. Evaluation of TMPA 3B42V7, GPM IMERG and CMPA precipitation estimates in Guangdong Province, China. Int. J. Clim. 2018, 39, 738-755. [CrossRef]

33. Arshad, M.; Ma, X.; Yin, J.; Ullah, W.; Ali, G.; Ullah, S.; Liu, M.; Shahzaman, M.; Ullah, I. Evaluation of GPM-IMERG and TRMM-3B42 precipitation products over Pakistan-Science Direct. Atmos. Res. 2020, 249, 105341. [CrossRef]

34. Sahlu, D.; Nikolopoulos, E.I.; Moges, S.A. First Evaluation of the Integrated Multi-satellite Retrieval for GPM Day-1 IMERG over the upper Blue Nile Basin. J. Hydrometeorol. 2016, 17, 2875-2882. [CrossRef]

35. He, Z.; Yang, L.; Tian, F.; Ni, G.; Hou, A.; Lu, H. Intercomparisons of Rainfall Estimates from TRMM and GPM Multisatellite Products over the Upper Mekong River Basin. J. Hydrometeorol. 2017, 18, 413-430. [CrossRef]

36. Wang, Z.; Zhong, R.; Lai, C.; Chen, J. Evaluation of the GPM IMERG satellite-based precipitation products and the hydrological utility. Atmos. Res. 2017, 196, 151-163. [CrossRef]

37. Mahmoud, M.T.; Mohammed, S.A.; Hamouda, M.A.; Mohamed, M.M. Impact of Topography and Rainfall Intensity on the Accuracy of IMERG Precipitation Estimates in an Arid Region. Remote Sens. 2020, 13, 13. [CrossRef]

38. Xiao, D.; Zhao, Y.; Bai, H.; Tang, J.; Feng, P.; Liu, D. Simulation and Projection of Climate Change in North China Plain by CMIP5 Multi-model. Geogr. Geo-Inf. Sci. 2020, 36, 75-82.

39. Wang, C.; Tang, G.; Han, Z.; Guo, X.; Hong, Y. Global intercomparison and regional evaluation of GPM IMERG Version-03, Version-04 and its latest Version-05 precipitation products: Similarity, difference and improvements. J. Hydrol. 2018, 564, 342-356. [CrossRef]

40. Shen, L.; Lin, R.; Lu, L. Accuracy analysis of GPM IMERG and CMORPH precipitation data over North China. Clim. Res. 2020, 81, 55-70. [CrossRef]

41. Hong, Y.; Gochis, D.; Cheng, J.T.; Hsu, K.L.; Sorooshian, S. Evaluation of PERSIANN-CCS Rainfall Measurement Using the NAME Event Rain Gauge Network. J. Hydrometeorol. 2007, 8, 469. [CrossRef]

42. Gupta, H.V.; Kling, H.; Yilmaz, K.K. Decomposition of the mean squared error and NSE performance criteria: Implications for improving hydrological modelling. J. Hydrol. 2009, 377, 80-91. [CrossRef]

43. Kling, H.; Fuchs, M.; Paulin, M. Runoff conditions in the upper Danube basin under an ensemble of climate change scenarios. J. Hydrol. 2012, 424-425, 264-277. [CrossRef]

44. Zhou, B.; Zhai, P. A New Forecast Model Based on the Analog Method for Persistent Extreme Precipitation. Weather Forecast. 2016, 31, 1325-1341. [CrossRef] 